\title{
Kommissionen, Ausschüsse, Tribunale: Internationale Einrichtungen im Staatsvertrag von St. Germain
}

\author{
Commissions, Committees, Tribunals: International Bodies in the Treaty of St. Germain
}

Within the framework of the Paris Peace Treaties after World War I, a structure of various international bodies was created in order to implement numerous provisions. For the most part, their significance and their activities in the interwar period have receded into the background, especially concerning the lesser known parts of the Peace Treaties. Therefore, this contribution aims to provide an overview of the bodies linked to the Austrian Peace Treaty, the Treaty of St. Germain, showing their diversity regarding their significance, legal nature and legal basis, composition, scope of functions, duration and their relations with the Austrian Republic.

Keywords: Commissions - Interwar Period - Paris Peace Treaties - St. Germain - Treaty Bodies

\section{Einleitung}

Die Inklusion der Satzungen zweier internationaler Organisationen im modernen Sinn, des Völkerbunds und der Internationalen Arbeitsorganisation (ILO), zählt zu den prominentesten Aspekten der Pariser Friedensverträge und stellt eines der Merkmale dar, durch die sich die Verträge von bisherigen Friedensverträgen unterscheiden. Weitaus weniger bekannt sind jedoch die zahlreichen anderen in den jeweiligen Verträgen vorgesehenen Einrichtungen, die - im Gegensatz zur universellen, über den Zweck der Friedensregelung im aktuellen Fall hinausreichenden Zielsetzung und eigenständigen Organisation des Völkerbunds bzw. der ILO - allein der Durchführung bestimmter Vertragsregelungen dienen. ${ }^{1}$ Einblick in die Tätigkeit dieser Einrichtungen geben zum Teil Darstellungen zu den materiellen

\footnotetext{
${ }^{1}$ Dementsprechend werden auch die durch diese Satzungen oder in ihrem Gefolge geschaffenen Einrichtungen, darunter der Ständige Internationale Gerichtshof, hier nicht näher behandelt.
}

Vertragsbestimmungen, auf die sie sich beziehen. Werke, die sich mit den Einrichtungen als solchen und deren Bedeutung auseinandersetzen, bilden die Ausnahme. ${ }^{2}$ Dieser Beitrag versucht daher, einen Überblick über die im Vertrag von St. Germain (VSG) enthaltenen Einrichtungen zu geben, wobei sich auch die Gliederung an der Struktur des Staatsvertrags orientiert.

\section{Terminologische Vorbemerkung}

Das gewählte Thema bringt zunächst eine Fülle von terminologischen Herausforderungen mit sich. Im geltenden Völkerrecht geht mit der Vielfalt der Gebilde ein Mangel an einheitlicher Begrifflichkeit einher, der eine klare Abgrenzung und Systematisierung der Einrichtungen untereinander erschwerte. Dafür gibt es mehrere Gründe, ein wesentlicher liegt und lag sicher in

\footnotetext{
${ }^{2}$ Genannt seien an dieser Stelle etwa FreISE, Kommissionen und BUIRETTE, Réparer.
} 
der Sache selbst begründet, da durch völkerrechtliche Verträge eingesetzte Einrichtungen jeweils im Hinblick auf vertragsspezifische Funktionen ausgestaltet werden und sich damit so vielfältig wie die Verträge selbst darstellen. Verstärkend kommen die Expansion des Völkerrechts ${ }^{3}$ und der internationalen Akteure ${ }^{4}$ in den letzten Jahrzehnten und die Problematik hinzu, dass heutige Begriffe in manchen Fällen nicht ohne Weiteres übernommen werden können und näherer Erläuterung bedürfen.

Sowohl die Bezeichnung der "Institution“ als auch die der "Entität", des „Akteurs" und des "Organs" werden (auch) in jeweils anderen $\mathrm{Zu}$ sammenhängen gebraucht und ihre Verwendung könnte daher missverständlich sein. Am ehesten käme noch der Begriff des "Vertragsorgans" (,treaty body“) in Betracht; auch dieser ist jedoch in funktionaler Hinsicht eingeschränk $\mathrm{t}^{5}$ und bezieht sich in erster Linie auf bestimmte Bereiche, nämlich den internationalen Menschenrechtsschutz $^{6}$ sowie das internationale Umweltrecht. ${ }^{7}$ Der Begriff der „Kommission“ wiederum wird im VSG nicht für Gebilde gebraucht, die aus funktionaler Sicht der Judikative zuzuordnen

\footnotetext{
${ }^{3}$ Vgl. etwa Wolfrum, Introduction 1.

${ }^{4}$ Zur Notwendigkeit einer Definition des Begriffs des „nicht-staatlichen Akteurs“ siehe DuPUY, Proliferation 544-546, die die verbreitete Verwendung im weitesten Sinn (im Sinn von Einrichtungen, die keine Staaten und von Bedeutung für das Völkerrecht sind) kritisiert und dafür eintritt, den Begriff auf bestimmte Einheiten (unter Ausschluss insbesondere Internationaler Organisationen und von „institutions of judicial decisionmaking“) einzuschränken; von einem solchen engen Begriffsverständnis gehen etwa auch die Herausgeber des Handbuchs für Völkerrecht aus, die die nicht-staatlichen Akteure jeweils separat behandeln. Vgl. REINISCH, Handbuch 276-288.

${ }^{5}$ Einrichtungen, deren Hauptaufgabe der judiziellen Funktion zuzuordnen ist, werden üblicherweise nicht als "treaty bodies", sondern als "courts" oder "tribunals" bezeichnet.

${ }^{6}$ Für diese ist die Zusammensetzung aus unabhängigen und unparteilichen Experten kennzeichnend; ihre Hauptfunktion liegt in der Erstellung von Berichten (vgl. STOLL, Human Rights, Treaty Bodies Rz 10, 12).
}

wären ${ }^{8}$ - in der amtlichen Übersetzung wird er zudem zumeist ${ }^{9}$ als „Ausschuss“ wiedergegeben, wiewohl oftmals eher die Bezeichnung „Kommission" gebräuchlich war. ${ }^{10}$ Zur Ausübung schiedsrichterlicher und strafrechtlicher Entscheidungsbefugnisse wurden weitere, im Französischen ${ }^{11}$ als "tribunaux" bezeichnete Einrichtungen (in der Übersetzung als "Gerichtshöfe" bzw. "Gerichte“ wiedergegeben) geschaffen. Im Folgenden wird daher ein möglichst weites Begriffsverständnis zugrunde gelegt. Als Überbegriff soll trotz bzw. gerade wegen seiner Abstraktheit jener der "Einrichtung“ fungieren, da es in der deutschen völkerrechtlichen Terminologie keinen dem englischen ",body“ korrespondierenden Terminus gibt. Darüber hinaus wurde sowohl unter den wirtschaftlichen als auch unter den finanziellen Bestimmungen die Entscheidung einzelner Fragen durch Schiedsspruch vorgesehen, da der Vertrag an zahlreichen Stellen keine abschließenden Regelungen traf, sondern zum Abschluss von Übereinkommen zwischen den betroffenen Staaten verpflichtete und für die Entscheidung über strittige Punkte die Ernennung eines oder mehrerer Schiedsrichter vorsah.

\footnotetext{
${ }^{7} \mathrm{Im}$ Vergleich zu jenen des Menschenrechtsschutzes sind die Funktionen der Vertragsorgane im Umweltrecht extensiver, vgl. RüBENS, Environmental Treaty Bodies Rz 38-52.

8 "Mixed claims commissions" bestanden im 18. Jahrhundert, bis sie von den "mixed tribunals" abgelöst wurden; im VSG sind bereits letztere vorgesehen, vgl. Dolzer, Mixed Claims Commissions Rz 2, siehe dazu noch unten unter "Gemischte Schiedsgerichtshöfe".

${ }^{9}$ Eine Ausnahme bilden die Erwähnungen in Art. 132 Abs. 5, Art. 136 Abs. 3, Art. 163 und Art. 248 Pkt. 4 Abs. 2, und die Europäische und Internationale Donaukommission.

${ }^{10}$ Vgl. RATHMANNER, Reparationskommission 81.

${ }^{11}$ Gemäß Art. 381 Abs. 2 ist - mit Ausnahme der Satzungen des Völkerbundes und der Internationalen Arbeitsorganisation, für die auch die englische Fassung maßgeblich ist - die authentische Fassung des Vertrags die französische.
} 
Auch bei einzelnen Zuständigkeiten anderer Einrichtungen wurde alternativ die Möglichkeit der Ernennung eines oder mehrerer Schiedsrichter eröffnet; daneben bestanden Spezialfälle, von denen im Folgenden nur jener der Aufteilung der Flussschiffe näher behandelt wird.

\section{Grenzen (VSG Teil II)}

Die Grenzfestlegung im Gelände wurde gemäß Art. 29 VSG den Grenzregelungsausschüssen übertragen.

Entsprechend einer für Grenzfestlegungen üblichen Regelungstechnik ${ }^{12}$ wurden die Bestimmungen der Friedensverträge in sogenannten „Instruktionen betreffend die Grenzregelungsausschüsse" präzisiert, die allgemeine, organisatorische und technische Belange betrafen. Verantwortlich für diese Instruktionen ${ }^{13}$ (und gemäß den Instruktionen auch für die Akkreditierung der Kommissionäre der Staaten) waren die Friedenskonferenz ${ }^{14}$ und ihr nachfolgend die Botschafterkonferenz, ${ }^{15}$ der als politisch übergeord-

\footnotetext{
12 Vgl. JONES, Boundary-Making 180, der eindeutige Instruktionen für solche Grenzkommissionen empfiehlt. ${ }^{13}$ Die "Instructions to the Demarcation Commissions, pursuant to the Peace Treaties" finden sich bei den Protokollen der Zentralgrenzkommission (ÖStA, AdR, AAng BKA/AA, NPA, Kart. 239, Liasse Österreich 9/I - Verhandlungsschriften der österr. Zentralgrenzkommission; zu dieser noch unten) und sind bei JONES, Boundary-Making, Appendix I 229-239, abgedruckt. $\mathrm{Zu}$ unterscheiden sind sie von den internen Instruktionen an die österreichischen Vertreter der Grenzregelungsausschüsse (zu deren Inhalt vgl. Zentralgrenzkommission [im Folgenden: ZGK], Protokoll Nr. 31, Beilage 13 zu Pkt. 224 vom 7. und 8. 7. 1920).

${ }^{14}$ Die Instruktionen gehen zurück auf den Beschluss des Obersten Rates im Oktober 1919 und wurden von der Botschafterkonferenz am 22.7. 1920 redigiert (ZGK, Protokoll Nr. 42, Pkt. 301 vom 5. 8. 1920). Von der Zentralgrenzkommission zunächst als Verstoß gegen die Bestimmungen des Friedensvertrags bewertet (Prot. Nr. 26, Pkt. 202 vom 19. 7. 1920 [richtig wohl:
}

neter, koordinierender Instanz eine entscheidende Bedeutung im Prozess der Grenzfestsetzung zukam.

Für jede sich aus dem Staatsvertrag ergebende neue Grenze war pro Nachbarstaat ein eigener Grenzregelungsausschuss (GRA) vorgesehen, dessen grundlegende Zusammensetzung sich unter den politischen Bestimmungen zum jeweiligen Staat fand. Insgesamt regelte der VSG die Zusammensetzung von drei derartigen Ausschüssen: des österreichisch-italienischen (Art. 36 Abs. 3), des österreichisch-jugoslawischen (Art. 48 Abs. 1) sowie des österreichischtschechoslowakischen (Art. 55 Abs. 1) GRA. Die letztgenannten sollten aus sieben Mitgliedern, je einem Delegierten der alliierten und assoziierten Hauptmächte (AAHM) und jeweils einem Vertreter der beiden beteiligen Staaten, bestehen; da Italien zugleich AAHM und Nachbarstaat war, sollte sich der italienisch-österreichischen GRA nur aus fünf Delegierten, neben dem italienischen und dem österreichischen drei aus dem Kreis der AAHM, zusammensetzen. Die Rechtsgrundlage für den österreichisch-ungarischen GRA, der ebenfalls aus sieben Mitgliedern beste-

19.6. 1920]), war Anfang Juli die Übersendung eines Aide-Mémoires an die Botschafterkonferenz (Prot. Nr. 30, Pkt. 220 vom 6. 7. 1920) erfolgt, die sich in ihrer Antwort vom 27.7. $1920 \mathrm{zu}$ versichern genötigt sah, dass es sich bei den Instruktionen lediglich um „Richtlinien allgemeiner Natur" handle, die - wie seitens Österreichs befürchtet - die Vertragsbestimmungen weder ändern noch einschränken würden. (Antwort der Botschafterkonferenz, abgedruckt als Beilage $17 \mathrm{zu}$ Prot. Nr. 44, Pkt. 321 vom 14. 8. 1920).

${ }^{15}$ Die Einrichtung der Botschafterkonferenz, bestehend aus den Botschaftern der USA, Großbritanniens, Italiens und Japans und dem französischen Außenminister unter dem nominellen Vorsitz des französischen Ministerpräsidenten, wurde mit Resolution des Obersten Rates vom 13. 12. 1919 endgültig beschlossen und sie nahm fünf Tage nach dem offiziellen Ende der Friedenskonferenz am 21. 1. 1920 ihre Tätigkeit auf. Vgl. HEIDEKING, Areopag 19-22. 
hen sollte, fand sich nicht im Vertrag von St. Germain, sondern (nur) im Vertrag von Trianon (Art. 71 Abs. 2 VT). Die Ausschüsse hatten jeweils binnen zwei Wochen nach Inkrafttreten des VSG zusammenzutreten (Art. 36 Abs. 3, Art. 55 Abs. 1, Art. 48 Abs. 1) und mit Stimmenmehrheit zu entscheiden (Art. 29 Abs. 3), der Vorsitz war einem Kommissär aus dem Kreise der nicht unmittelbar interessierten Mächte, d.h. der AAHM, vorbehalten. ${ }^{16}$ Tatsächlich sollten an den Beratungen des österreichisch-jugoslawischen sowie des österreichisch-tschechoslowakischen GRA nur Vertreter dreier AAHM teilnehmen; die japanischen Vertreter wurden zwar ernannt, waren aber nur im österreichisch-italienischen GRA vertreten. ${ }^{17}$ Der österreichisch-ungarische Ausschuss konstituierte sich von vornherein ohne japanische und US-amerikanische Vertreter. ${ }^{18}$

Innerstaatlich erfolgte die Koordination und Organisation der Grenzfestlegung durch die sogenannte Zentralgrenzkommission in Wien im Zusammenwirken mit drei „Länderzentralbureaus“

${ }^{16}$ Vgl. Instruktionen, Pkt. II. C, in: JONES, BoundaryMaking, Appendix I, 229-239, hier 231; in den konstituierenden Sitzungen wurde jeweils der Kommissär Frankreichs zum Vorsitzenden des österreichisch-italienischen bzw. des österreichisch-tschechoslowakischen GRA und der britische Kommissär zum Vorsitzenden des österreichisch-jugoslawischen GRA gewählt. Vgl. ZGK, Prot. Nr. 41, Pkt. 289 und 293 vom 2. 8. 1920 und Nr. 42, Pkt. 308 vom 5. 8. 1920.

17 KÖNIG, Österreichs Grenzen Rz. 29. Ausführlich zur Zusammensetzung des österreichisch-italienischen GRA EGGER, Teilung 29-34.

18 Vgl. KÖNIG, Österreichs Grenzen Rz. 62.

${ }^{19} \mathrm{Vgl}$. $\S 1$ der „Organischen Bestimmungen für die Einrichtung eines Dienstes zur Regelung und Festsetzung der neuen Staatsgrenze“", die mit Kabinettsratsbeschluss vom 31. 10. 1919 genehmigt worden waren.

${ }^{20}$ Organische Grundsätze, §2. Zur konstituierenden Sitzung am 27.10. 1919 entsandten die Staatskanzlei sowie die Staatsämter für Äußeres, Heereswesen, Handel und Gewerbe, Industrie und Bauten und Verkehrswesen jeweils einen Vertreter. In der Geschäftsordnung (§ 1) wurde zudem ein Vertreter des Staatsamtes für Finanzen vorgesehen, der schließlich ab der 5. Sitzung (Nr. 5 Pkt. 25) seine Tätigkeit aufnahm. In weiterer Folge kamen noch jeweils ein ständiger Vertreter in Wien, Graz und Innsbruck. ${ }^{19}$ Die Zentralgrenzkommission unterstand unmittelbar dem Kabinettsrat und bestand aus den Vertretern der an der Durchführung des II. Teiles des Staatsvertrags „zunächst beteiligten“ Staatsämter;"20 sie beriet bereits vor Zusammentreten der einzelnen GRA über Besetzungs-, Finanzierungs- und Organisationsfragen sowie über vorläufige Regelungen und Angelegenheiten der Grenzfestlegung, insbesondere auch betreffend die direkten Verhandlungen mit der Tschechoslowakei. Was die Auswahl der österreichischen Vertreter für die GRA anlangt, so wurden zunächst - in Abstimmung mit den interessierten Ländern - diplomatisch versierte, sprachlich qualifizierte und aus Sicht der unmittelbar beteiligten Länder vertrauenswürdige Kräfte des auswärtigen oder militärischen Staatsdienstes in Betracht gezogen, während das Staatsamt für Äußeres Offiziere für die bessere Wahl hielt. ${ }^{21}$ Dementsprechend wur-

des Staatsamtes der Finanzen (18. 11. 1919) und des Staatsamtes für Land- und Forstwirtschaft (14. 2. 1920) dazu (Nr. 14, Pkt. 91). Den Vorsitz führte den organischen Grundsätzen entsprechend ein Vertreter des Staatsamts für Inneres und Unterricht. (ZGK, Prot. Nr. 1).

${ }^{21}$ ZGK, Prot. Nr. 1, Pkt. 3 vom 27. 10. 1919 sowie Prot. Nr. 4, Pkt. 19 vom 6. 11. 1919. Das Staatsamt für Äußeres betonte (weniger als das Staatsamt für Heereswesen), dass „einem alten internationalen Brauch entsprechend" ausschließlich Offiziere als Kommissäre in Frage kämen. Vgl. Vortrag für den Kabinettsrat über die Einrichtung der Länderzentralbureaus in Innsbruck, Graz und Wien, ZGK, Prot. Nr. 6, Pkt. 34 vom 19. 11. 1919. Da in den organischen Bestimmungen die Ernennung der Vorstände der Länderzentralbureaus als Kommissäre vorgesehen worden war, einigte man sich hier schließlich auf deren zivile Leitung und die Beigabe militärischer Sachverständiger, damit diese im Falle einer künftigen Nominierung als Vertreter im GRA mit den bisherigen Geschehnissen bereits vertraut wären. Vgl. Vortrag für den Kabinettsrat über die Einrichtung der Länderzentralbureaus in Innsbruck, Graz und Wien, ZGK, Prot. Nr. 6, Pkt. 34 vom 19. 11. 1919. 
den Mitte April 1920 vom Staatsamt für Heereswesen als militärische Sachverständige ${ }^{22}$ für die Länderbureaus Major Eduard Steyrer nach Graz, Oberstleutnant Hugo Metzner nach Wien und Oberstleutnant Alfons Bernhard nach Innsbruck bestimmt ${ }^{23}$ und in der Folge als Kommissäre für den jeweiligen GRA ernannt. ${ }^{24}$ Die Konstituierung der GRA erfolgte unter Teilnahme der österreichischen Vertreter Ende Juli 1920 in Paris;,25 Österreich konnte sich mit seinem Wunsch nach Sitznahme auf österreichischem Gebiet ${ }^{26}$ nicht durchsetzen. ${ }^{27}$

Im Allgemeinen lässt sich der Prozess der Grenzfestlegung in mehrere Stadien unterteilen, wobei nach der Entscheidung über die Zuteilung des betreffenden Territoriums die Phase der Grenzfestlegung im Sinne einer vertraglichen Definition von der Vermarkung im Gelände unterschieden werden kann.28 Zumeist enthalten die Bestimmungen über die Grenzfestlegung auch Bestimmungen über die Vermarkung oder die künftige Verwaltung (als weiteres Stadium). ${ }^{29}$ Es ist jedoch kaum möglich, eine Grenze vertraglich so exakt zu umschreiben, dass dem zur Durchführung berufenen GRA bloß die technische Umsetzung, d.h. allein die Durchführung der Vermarkung im Gelände verbleibt, sodass sich daraus

\footnotetext{
${ }^{22}$ Bis 1918 hatten sich topographische Landesaufnahme und Kartographie noch in militärischer Hand befunden, namentlich der des militärgeographischen Instituts, an dem auch die entsprechende Ausbildung erfolgte. Vgl. STRENN, Josefstadt 18-20, 23, 31.

23 Vgl. ZGK, Prot. Nr. 20, Pkt. 143 vom 15. 4. 1920. Aus den Protokollen geht die Qualifikation der Ernannten nicht hervor, die Auswahl erfolgte durch das Staatsamt für Heerwesen. Der bekannteste unter den dreien war wohl Hugo Metzner als anerkannter Spezialist für artilleristisches Schießwesen und Ballistik (!), vgl. HuMMELBERGER, Metzner 253. Bernhard war seit 1919 bereits im Ruhestand, vgl. Archivinformationssystem OeStA, Bestand Bernhard, Alfons.

${ }^{24}$ ZGK, Prot. Nr. 31, Pkt. 224 vom 7. und 8. 7. 1920. Oberst Bernhard wurde später von Gerneral Hervay abgelöst, vgl. KÖNIG, Österreichs Grenzen Rz 29. Für den österrreichisch-ungarischen GRA war zunächst Oberst Robert Schuch (ZGK, Prot. Nr. 5, Pkt. 52), vorgeschlagen worden; ernannt wurde schließlich MR
}

bei der Festlegung des endgültigen Grenzverlaufs ein gewisser Entscheidungsspielraum ergibt. ${ }^{30}$ So auch im VSG: Nach der Beschreibung der festzulegenden Grenzen in Art. 27 sowie des Abstimmungsgebietes in Art. 49 Abs. 2 bzw. Art. 50 Abs. 1 bezogen sich Art. 29 bis 35 in erster Linie auf die Vermarkung und Verwaltung der Grenzen. Die Kernbestimmung zur Kompetenz der GRA stellt Art. 29 Abs. 2 dar, der den GRA „jegliche Machtbefugnis" - auf Antrag selbst zur Revision der durch Verwaltungsgrenzen bestimmten Teilstrecken der neu festzulegenden internationalen Grenzen - übertrug; Art. 30 überließ ihnen bei den durch Flüsse bestimmten Grenzen die Entscheidung zwischen festen und beweglichen Grenzen. Noch weiter gingen die Instruktionen, die ausdrücklich festhielten, dass auch bei Fehlen einer vertraglichen Spezialbestimmung in wenig bedeutenden Fällen mit einstimmiger Entscheidung die Zuordnung einer im Vertrag namentlich genannten Örtlichkeit geändert werden konnte. ${ }^{31}$ Ein möglichst weiter Entscheidungsspielraum lag durchaus im Interesse Österreichs, das zudem (vergeblich) eine ähnliche Ermächtigung erhofft hatte, wie sie aus der Geleitnote zum Vertrag von Trianon den ungari-

Dr. Stefan Neugebauer, vgl. KÖNIG, Österreichs Grenzen Rz 64 .

${ }^{25}$ ZGK, Prot. Nr. 41 vom 2. 8. 1920.

26 ZGK, Prot. Nr. 4, Pkt. 17 und 18.

27 ZGK Prot. Nr. 41, S. 289 vom 2. 8. 1920, ZGK, Prot. Nr. 41, S. 293 vom 2. 8. 1920. Der österreichisch-tschechoslowakische Ausschuss legte keinen Sitz fest, der österreichisch-jugoslawische entschied sich auf Antrag Österreichs für eine Alternierung zwischen Marburg und Graz.

${ }^{28}$ In manchen Fällen wird der Begriff der Grenzfestlegung allerdings auch in einem weiteren, die Vermarkung miteinbeziehenden Sinne verwendet. Vgl. JONES, Boundary-Making 57.

${ }^{29}$ Ebd. 5.

${ }^{30}$ Ebd. 5.

${ }^{31}$ Instruktionen, Pkt. I, in: JONES, Boundary-Making 229. 
schen (und damit auch dem dort geregelten österreichisch-ungarischen GRA) zugestanden worden war: Danach konnten sich die GRA in den Fällen, in denen sie eine Abänderung der im Friedensvertrag festgelegten Grenzen für unabweislich hielten, mit einem Bericht an den Völkerbund wenden. ${ }^{32}$

Die Aufgaben der GRA ließen sich nach den Instruktionen in 1. den Entwurf eines Arbeitsplanes, 2. die Festlegung der Grenzlinie, 3. die Vermarkung der Grenzlinie im Gelände, 4. die Überprüfung der Arbeiten im Gelände und die Verfassung der offiziellen Vermessungsprotokolle unterteilen. ${ }^{33}$ Wie nur aus diesen Instruktionen, nicht aus dem Vertragstext hervorgeht, oblag die Durchführung der notwendigen Tätigkeiten großteils den jeweiligen interessierten Staaten: Diese sollten die Vorarbeiten vornehmen und die Festlegung der endgültigen Grenzlinie vereinbaren. An den GRA sollten nur die strittigen Punkte bzw. Änderungsvorschläge herangetragen werden. Nach den Vorgaben der GRA hatten sie auch die Vermarkung durchzuführen ${ }^{34}$ und gem. Art. 29 Abs. 4 VSG für die Kosten der Ausschüsse - mit Ausnahme der gewöhnlichen Bezüge, d.h. der Gehälter der jeweiligen Mitglieder ${ }^{35}$ - aufzukommen. ${ }^{36}$ Die Dauer der Tätigkeit der GRA war

\footnotetext{
32 Eine Anfrage an die Botschafterkonferenz wurde abschlägig beantwortet, vgl. ZGK, Prot. Nr. 44, Beilage 17 zu Pkt. 321 vom 14. 8. 1920.

${ }^{3}$ Instruktionen, in: JONES, Boundary-Making 232.

${ }^{34}$ Einen anschaulichen Überblick über den Ablauf der Vermarkungstätigkeit geben DOTTER, WEDRAC, Preis des Friedens 178-186.

${ }^{35}$ Genaue Regelungen zu den Kosten enthalten die Instruktionen (Pkt. II F, JONES, Boundary-Making 234) und - für den tschechoslowakischen GRA - das Prager Übereinkommen vom 21. 8. 1921.

${ }^{36}$ In Österreich hatte die mangelnde Begrenzung der Dauer dieser finanziellen Belastung zu Bedenken Anlass gegeben, vgl. ZGK, Prot. Nr. 27, Pkt. 204 vom 24. 7. 1920.

37 Vgl. EGGER, Teilung 30. Der mit der aufwendigsten Grenzziehung betraute österreichisch-italienische Ausschuss bestand bis 1924; die offizielle Übergabe der Schussdokumente erfolgte in Rom im November 1924, vgl. EGGER, Teilung 107.
}

im VSG nicht festgelegt worden und ergab sich daher aus der Erfüllung der ihnen überantworteten Aufgabe, d.h. dem Abschluss der Grenzfestlegung, wobei die Ausschüsse von Beginn an unter großem Zeitdruck standen. ${ }^{37}$

So großes Aufsehen die neue Grenzziehung aus inhaltlicher Sicht erregt hatte, so wenig Besonderheiten wies die Art der Regelung und ihre Durchführung auf: Sowohl die Grenzbeschreibungen als auch die Einsetzung von Grenzregelungsausschüssen stellen keine Neuerung gegenüber bisherigen Vorgehensweisen dar, ${ }^{38}$ auch Detailregelungen wie etwa die grundsätzliche Kostenteilung zwischen den betroffenen Staaten erschienen nicht außergewöhnlich. ${ }^{39}$ Als unüblich war allenfalls die Art der Zusammensetzung anzusehen, wonach nicht nur Delegationen der beteiligten Staaten, sondern auch der Siegermächte als Mitglieder vertreten waren, was verhältnismäßig große Ausschüsse zur Folge hatte. ${ }^{40}$ Wenngleich die Stellung der „nicht interessierten Staaten" trotz gleicher Stimmgewichtung letzten Endes der von Neutralen glich, ${ }^{41}$ darf nicht vergessen werden, dass es sich dabei um Vertreter der Siegermächte handelte. Darauf dürfte sich auch die österreichische Kritik an den Instruktionen

${ }^{38}$ Vgl. nur beispielsweise den Ersten Pariser Frieden zwischen Österreich und Frankreich vom 30.5. 1814, Art. III Zif. 7 Abs. 2 oder den Frieden von Frankfurt zwischen Frankreich und dem Deutschen Reich vom 10. 5. 1871, Art. 1 Abs. 2.

39 Siehe JONES, Boundary-Making 176-178, der die Friedensverträge im Allgemeinen, den VSG im Besonderen, als Beispiel für jene Verträge heranzieht, in denen eine Halbteilung der Kosten zwischen den beiden Staaten vorgesehen ist.

${ }^{40}$ Zur typischen Zusammensetzung siehe JONES, Boundary-Making 167-169, der die Delegierten der Siegermächte jedoch wie neutrale Mitglieder behandelt.

${ }^{41}$ Davon scheint auch JONES, Boundary-Making 168, auszugehen, der im Kapitel über neutrale Mitglieder exemplarisch die Kommissionen nach den Pariser Friedensverträgen und ihre Größe hervorhebt. 
für die GRA hinsichtlich des „,verhandlungstechnischen Teils" bezogen haben, der "derart ungünstig sei, daß die Tätigkeit der Grenzregulierungsausschüsse eine Erfüllung unserer grenzpolitischen Wünsche kaum erwarten lasse."4243 Diese Konstellation dürfte auch dazu beigetragen haben, dass über die Festlegung der Grenze mit der Tschechoslowakei zusätzlich bilaterale Verhandlungen geführt wurden.

\section{Politische Bestimmungen über Europa, SHS-Staat (VSG Teil III, Abschnitt II)}

Im Hinblick auf das "Selbstbestimmungsrecht" der Völker berief Art. 49 Abs. 1 die Einwohner des „Gebiets von Klagenfurt“ zur Entscheidung über die Zugehörigkeit des Gebietes im Wege einer Volksabstimmung, deren Durchführung in Art. 50 näher geregelt wurde. Das Gebiet wurde gem. Abs. 1 leg.cit. in zwei Zonen unterteilt, von denen die nördliche unter österreichische, die südliche unter Verwaltung des SHS-Staats gestellt wurde (Art. 50 Abs. 4 und 5). Um die Unparteilichkeit dieser Verwaltung sicherzustellen und die Abhaltung der Volksabstimmung vorzubereiten, wurde das gesamte Abstimmungsgebiet gem. Art. 50 Abs. 2 der Aufsicht eines Ausschusses unterstellt, der von den Zeitgenossen

\footnotetext{
42 Prot. Nr. 26, Pkt. 202 vom 19. 7. 1920.

${ }^{43} \mathrm{Zu}$ der besonders schwierigen Situation im österreichisch-italienischen GRA, namentlich auch der Brennergrenze, siehe DOTTER, WEDRAC, Preis des Friedens, 164-178.

${ }^{44}$ Vgl. etwa die Berichterstattung in der Zeitung „Freie Stimmen“ von Mai 1919 bis November 1920, in der auch die an die Bewohner des Abstimmungsgebietes adressierten „Kundmachungen“ der Plebiszitkommission verlautbart wurden, siehe z.B. die "1. Kundmachung an die Bevölkerung des Kärntner Abstimmungs-Gebietes" vom 10. 8. 1920, in: Freie Stimmen Nr. 190 v. 21. 8. 1920, 1.
}

mit dem Namen „Plebiszitkommission“ versehen wurde ${ }^{44}$ und sich zumeist auch unter dieser Bezeichnung in der Literatur findet.

Die Zusammensetzung des Ausschusses regelte Art. 50 Abs. 3: Dementsprechend bestand er sowohl aus Vertretern von vier der AAHM (mit Ausnahme Japans) als auch der beiden betroffenen Staaten. Pro vertretenem Staat war jeweils ein Mitglied vorgesehen. Das von Österreich ernannte Mitglied war nur den Beratungen betreffend die von ihm verwaltete nördliche Zone, das Mitglied des SHS-Staats nur denen betreffend die von diesem Staat verwaltete südliche Zone zuzuziehen. Die Entscheidung sollte mit Stimmenmehrheit erfolgen. Als die USA mangels Ratifizierung von der Entsendung eines Vertreters absahen, ${ }^{45}$ entschied die Botschafterkonferenz, dass dem österreichischen und jugoslawischen Vertreter nur eine beratende Funktion zukommen sollte. ${ }^{46}$ Auch die Festlegung, dass jeweils nur ein Vertreter der beteiligten Staaten an den Beratungen teilnehmen sollte, wurde in der Praxis nicht eingehalten, da von Beginn an die Angelegenheiten der jeweiligen Zone nicht getrennt, sondern in Anwesenheit beider Vertreter besprochen wurden, die jeweils vor den Abstimmungen Gelegenheit zur Stellungnahme bekamen. ${ }^{47}$

Die beiden Aufgabenbereiche des Ausschusses werden in Art. 50 Abs. 6 und 7 näher umschrieben: So hatte der Ausschuss in Bezug auf die Verwaltung des Gebiets gem. Abs. 6 leg.cit. über die Herabsetzung der jeweiligen Truppen auf das

\footnotetext{
45 Wambaugh, Plebiscites I, 185.

${ }^{46}$ Die Entscheidung wurde den beiden Regierungen mit (jeweils gleichlautender) Note vom 8. 6. (als Ergänzung der Note vom 1. 6.) mitgeteilt; die jugoslawische Version beider Noten ist abgedruckt bei WAMBAUGH, Plebsicites II, 128. Prompt protestierten beide Regierungen gegen die aus ihrer Sicht vertragswidrige Anordnung; die Botschafterkonferenz entschloss sich gegen die Abänderung eines bereits gefassten Beschlusses mit eben diesem Argument, obwohl der französische Delegierte auf die Möglichkeit einer Klage beim Völkerbund hinwies. HEIDEKING, Areopag 146.

47 WAMBAUGH, Plebiscites I, 186.
} 
zur Aufrechterhaltung der Ordnung notwendige Maß - bis zu deren ehestmöglichen Ersatz durch Polizeikräfte - zu entscheiden und deren Tätigkeit zu überwachen. Gem. Abs. 7 leg.cit. hatte er die Abhaltung der Volksabstimmung zu organisieren und dabei „alle Maßnahmen zu treffen, die er zur Sicherung einer freien, unbeeinflussten und geheimen Stimmabgabe für notwendig hält". Die Regelung der Modalitäten der Abstimmung (Zeitpunkt, Stimmberechtigung, Ermittlung des Ergebnisses, Kundmachung) folgte in Art. 50 Abs. 8 bis 13. In diesem Zusammenhang oblag dem Ausschuss die Festlegung des genauen Abstimmungszeitpunkts sowie die Kundmachung des Ergebnisses; in einer gesonderten Mitteilung an die AAHM hatte er zudem Rechenschaft über den Ablauf abzulegen. Im Anschluss hatte die Erstreckung der Staatsgewalt auf die je nach Ausgang der Abstimmung - von dem jeweiligen Staat noch nicht verwaltete Zone im Einvernehmen mit dem Ausschuss zu erfolgen. Im Gegensatz zu den anderen Einrichtungen war die Dauer der Tätigkeit des Ausschusses im VSG ausdrücklich mit der Sicherstellung der regulären Verwaltung durch den Staat, dem das Gebiet aufgrund der Volksabstimmung zufallen sollte, begrenzt worden (Art. 50 Abs. 16).

Im Vergleich zu anderen Vertragsbestimmungen hatten die Regelungen über die Volksabstimmung und ihre Organisation auf der Pariser Friedenskonferenz viel Raum eingenommen. Dies lag nicht nur an der Kärntner Situation, die angesichts des Aufflammens von Kämpfen in regelmäßigen Abständen die Aufmerksamkeit der Siegermächte beanspruchte, ${ }^{48}$ sondern auch an den

\footnotetext{
${ }^{48}$ Allein seitens der deutschösterreichischen Delegation wurden insgesamt 13 Noten „wegen der Ereignisse an der südslawischen Front" eingereicht; abgedruckt im Bericht der deutschösterreichischen Friedensdelegation.

${ }^{49}$ WAMBAUGH, Plebiscites I, 171.

50 Ebd. 185.

${ }^{51}$ Der Fregattenkapitän Albert Peter-Pirkham sprach französisch, englisch und italienisch und wurde später
}

Interessengegensätzen der Italiener und der Vertreter des SHS-Staates. Die grundsätzliche Herausforderung hatte darin bestanden, dass eine Grenzziehung im umstrittenen Gebiet anhand geographischer und sprachlicher Kriterien nicht möglich war, da der südliche Teil eine slowenischsprachige Mehrheit aufwies, zugleich aber geographisch vom restlichen Jugoslawien getrennt war. ${ }^{49}$ Die Entscheidung für ein Plebiszit und seine konkrete Ausgestaltung fiel jedoch erst nach langem Hin und Her, auf das auch die Besonderheiten der Kommission im Vergleich zu anderen Abstimmungskommissionen nach den Pariser Friedensverträgen zurückzuführen waren. Diese bezogen sich auf ihre Organisation und Zusammensetzung sowie auf ihre Aufgabe: Die Verwaltung des Abstimmungsgebiets erfolgte nicht durch die Kommission selbst, zusammengesetzt aus Vertretern der Siegermächte, sondern durch die beiden betroffenen Staaten unter Kontrolle der Plebiszitkommission, in der sie durch jeweils ein Mitglied vertreten waren und der keine eigenen Truppen beigestellt wurden. ${ }^{50}$ Die Mitglieder des Ausschusses, der unter der Leitung des Briten Col. PECK stand, wurden im April 1920 von der Botschafterkonferenz ernannt. Österreich entsandte Hauptmann Albert PeterPirkham, ${ }^{51}$ Jugoslawien Professor Dr. Civić, der bereits bei den Friedensverhandlungen als Gutachter tätig geworden war. Im Zuge der Streitigkeiten um die Öffnung der Demarkationslinie trat er zurück und wurde durch seinen bisherigen Stellvertreter, J. Jovanović, ersetzt. ${ }^{52}$ Die Botschafterkonferenz verlangte sowohl vom öster-

auch bei der Ödenburger Volksabstimmung eingesetzt. Vgl. Empfehlungsschreiben Karl Renners vom 22. 10. 1920, Privatschreiben des Staatssekretärs für Äußeres an den Kärntner Landeshauptmann vom 8. 11. 1920, ÖStA, AdR, AAng BKA/AA, NAR, Fach 4 Serie A Kart 124 Personalakt Albert Peter-Pirkham.

52 Wambaugh, Plebiscites I, 189. Die übrigen Mitglieder waren Graf Chambrun (Frankreich) und Fürst Borghese (Italien). 
reichischen als auch vom jugoslawischen Mitglied eine Ausstattung mit sämtlichen Vollmachten, um Verzögerungen durch Rückfragen bei der jeweiligen Regierung zu vermeiden, sowie die Sicherstellung einer Anordnungsbefugnis gegenüber den lokalen Zivil- und Militärbehörden zur Durchführung der Kommissionsentscheidungen. ${ }^{53}$ Nach Vorbereitung ihrer Tätigkeit ${ }^{54}$ in Abstimmung mit der Botschafterkonferenz in Paris $^{55}$ trafen die Kommissionsmitglieder am 21. Juli in Klagenfurt ein ${ }^{56}$ und hielten ihre konstituierende Sitzung in der Burg ab..$^{57}$ In dieser ersten Sitzung wurde die Einrichtung des Sekretariats $^{58}$ und die Beauftragung der Grenzkommission mit der genauen Abgrenzung des Abstimmungsgebiets beschlossen; der Präsident stellte die Grundzüge des geplanten Ablaufs und der Organisation ihrer Tätigkeit vor, die in der Sitzung vom 24. Juli 1920 einstimmig angenommen wurden.59 Die Organisationsstruktur sah eine grundsätzliche Selbstverwaltung durch die Einwohner und auf unterster, lokaler Ebene 12 Gemeinderäte vor, die mit dem Großteil der Vorbereitungs- und Durchführungsarbeiten betraut wurden. Die Auszählung der Stimmen wurde

\footnotetext{
${ }^{53}$ Vgl. Note vom 1. 6. 1920 an die jeweiligen Regierungen, abgedruckt bei WAMBAUGH, Plebiscites II, 126128, hier 128.

54 Österreich hatte sich zwar bereits im März 1920 mit der Bitte um vorzeitige Entsendung an die Botschafterkonferenz gewandt, diese sollte ihr jedoch aufgrund der ablehnenden Haltung der französischen Regierung nicht nachkommen. HEIDEKING, Areopag 146f.

55 Die Beratung über die in sieben Punkten zusammengefassten Empfehlungen fanden am 29. 4. statt und das überarbeitete Programm wurden den beiden Regierungen mit Note vom 1.6. und Ergänzungsnote vom 8. 6. 1920 mitgeteilt.

${ }^{56}$ Die Bevölkerung wurde von der Ankunft der Kommission mit einer an sie gerichteten Proklamation formell in Kenntnis gesetzt, abgedruckt bei WAMBAUGH, Plebiscites II, 128-9.

${ }^{57}$ Ebd. I, 185f.

${ }^{58}$ Dieses setzte sich aus einem britischen General und drei Sekretären zusammen, Ebd. I, 186.
}

den sechs Bezirksräten übertragen, die die Gemeinderäte in Hinblick auf die Vorbereitung der Abstimmung und ihre Verwaltungstätigkeit zu überwachen hatten und durch welche die gesamte Kommunikation der lokalen Verwaltung mit der Kommission vermittelt wurde. ${ }^{60}$ Hinzu kam ein Beratender Verwaltungsrat aus drei Personen, "which proved to be the most important feature of the organization". ${ }^{.1} \mathrm{Ihm}$ oblag die Überwachung der Unabhängigkeit der Verwaltung und er hatte der Kommission Bericht zu erstatten. Die Vorsitzenden der Bezirksräte und der Verwaltungsrat waren zu gleichen Teilen mit englischen, französischen und italienischen Vertretern besetzt, die Gemeinderäte wurden von der österreichischen und der jugoslawischen Kommission unter der lokalen Bevölkerung ausgewählt. ${ }^{62}$ Die Kommission wandte sich von Beginn an auch unmittelbar an die Bewohner des Abstimmungsgebiets, indem sie regelmäßig Proklamationen und Kundmachungen veröffentlichte.

Gem. Art. 50 Abs. 8 war die Volksabstimmung in der südlichen Zone innerhalb einer Frist von drei Monaten nach Inkrafttreten des VSG, das am 16. Juli 1920 erfolgte, durchzuführen. ${ }^{63}$ Nachdem

\footnotetext{
${ }^{59}$ Ebd. I, 188.

${ }^{60} \mathrm{Vgl}$. Ebd. I, 190.

${ }^{61}$ Ebd. I, 188.

62 Ebd. I, 188. Darüber hinaus wurde unter Berufung auf Art. 50 VSG ein eigener „Interalliierter PlebiszitGerichtshof" errichtet, der durch eine Reihe von spezifischen Delikten die Einhaltung der Kommissionsvorgaben für einen ungehinderten und unverfälschten Ablauf sicherstellen sollte, wobei es jedoch zu keinen Verfahren kam. Vgl. WAMBAUGH, Plebiscites I 189f. Zusammensetzung, Tatbestände und Sanktionen wurden als 6. Kundmachung im September 1920 publiziert, abgedruckt ebd. II, 133f. und in den Freien Stimmen Nr. 203 v. 5. 9. 1920, 1. Insgesamt waren für die Plebiszitkommission über 100 Personen tätig, vgl. Kärntner Landesarchiv, 10. Oktober 1920, 146.

${ }^{63}$ Die Instruktionen zur Durchführung datieren vom 16. 9. 1920 und sind abgedruckt bei WAMBAUGH, Plebiscites II, 135-157.
} 
man im August 1920 mit einer Durchführung bereits Anfang Oktober gerechnet hatte, ${ }^{64}$ setzte der Ausschuss das Abstimmungsdatum mit 10. Oktober fest. ${ }^{65}$ Im Zuge der Vorbereitungen stellte die Öffnung der Demarkationslinie das erste große (Streit-)Thema in der Kommission dar. Diese wurde zwar entsprechend den Vorgaben der Botschafterkonferenz von der Kommission einstimmig befürwortet, von Jugoslawien jedoch abgelehnt und erfolgte schließlich am 23. August 1920. ${ }^{66}$ Weitere Streitpunkte waren der Rückzug der jugoslawischen Truppen, ${ }^{67}$ Zahl und Mitglieder der örtlichen Gendarmerieeinheiten und die Frage der "staatlichen Kontrolle" von Privatbesitz in der von Jugoslawien verwalteten Zone. ${ }^{68}$ Nachdem trotz mehrmaliger Anfragen (sowohl von der österreichischen Regierung als auch dem Präsidenten der Kommission) die Botschafterkonferenz der Bitte um Zurverfügungstellung von Truppen zur Sicherung des ordnungsgemäBen Ablaufs der Abstimmung nicht nachkam, gelang es in letzter Minute, eine Entsendung alliierter Soldaten vom Heeresüberwachungsausschuss aus Wien zu erreichen. ${ }^{69}$ Am Abstimmungstag bereisten die Mitglieder der Kommission zudem selbst das Abstimmungsgebiet. ${ }^{70}$ Das Ergebnis wurde von allen unterzeichnet ${ }^{71}$ und nachdem die Kommission am 18. Oktober die Verwaltung der Zone selbst hatte übernehmen müssen - erging am 27. Oktober ihr Rechenschaftsbericht gemäß Art. 50 Abs. 13 VSG, in dem sie auf den reibungslosen Ablauf am Abstimmungstag hinwies und mögliche Gründe dafür anführte. ${ }^{72}$ Die Kommission blieb daraufhin noch

\footnotetext{
${ }^{64}$ Freie Stimmen, Nr. 194 v. 26. 8. 1920, 1.

${ }^{65}$ WAMBAUGH, Pleciscites I, 186.

66 Vgl. ebd. 188f.

${ }^{67}$ Während die österreichischen Truppen bereits bis 27. 8. 1920 ihre Zone geräumt hatten, zog sich der offizielle Abzug der jugoslawischen Truppen bis 14. 9. hin. WAMBAUGH, Plebiscites I, 191.

${ }^{68}$ Ebd. I, 191-193.

${ }^{69}$ Ebd. I, 195f

70 Ebd. I, 198.

71 Ebd. I, 198.
}

weitere sechs Wochen bis zur geordneten Übergabe der Zone am 18. November 1920 im Land. ${ }^{73}$

\section{Bestimmungen über Land-, See- und Luftstreitkräfte (VSG Teil V)}

$\mathrm{Zu}$ den bekanntesten Regelungen des Vertrags von St. Germain zählen die Abrüstungsbestimmungen, insbesondere die Abschaffung der allgemeinen Wehrpflicht (Art. 119) und die Beschränkung der Streitkräfte auf 30.000 Mann (Art. 120 Abs. 1). Weniger bekannt ist die Einrichtung dreier internationaler Ausschüsse, denen ein eigener Abschnitt des 5. Teils gewidmet war. Die Mitglieder des interalliierten Heeresüberwachungsausschusses (HÜA), des interalliierten Marineüberwachungsausschusses (MÜA) und des interalliierten Luftfahrtüberwachungsausschusses (LÜA) wurden von den AAHM ernannt und ihnen oblag die Überwachung der Durchführung all jener Bestimmungen über Landheer, Seemacht und Luftfahrt des VSG, für die eine zeitliche Grenze festgesetzt worden war (Art. 149). In gewisser Weise konnten sie als Fortsetzung der bereits seit Abschluss des Waffenstillstands in Österreich befindlichen Militärkommissionen und -missionen angesehen werden. ${ }^{74}$ Die allgemeine Zeitspanne für die Demobilisierung war gem. Art. 118 und Art. 156 mit drei Monaten ab Inkrafttreten des Vertrags bemessen. Eine dreimonatige Frist galt im Besonderen für

\footnotetext{
72 Ebd. I, 200. Neben der Präsenz der 58 Offiziere der Interalliierten Kontrollkommission werden die Siegessicherheit beider Parteien, die frühe Registrierung, das Alkoholverkaufsverbot, der von der Bevölkerung befürwortete Abstimmungsablauf, die Haltung der Gendarmerie und die Sicherstellung des Grundsatzes der geheimen Abstimmung als mitverantwortlich genannt. Ein Abdruck des Berichts findet sich bei WAMBAUGH, Plebiscites II, 159-162.

${ }^{73}$ Ebd. I, 200.

${ }^{74}$ FrEISE, Kommissionen 60.
} 
die Herabsetzung von Bewaffnung und Munition (Art. 130 Abs. 1, Art. 131 Abs. 2) sowie die Deponierung bzw. Auslieferung der überschießenden Bestände (Art. 130 Abs. 2, Art. 133), die Schließung oder Umwandlung aller Anlagen zur Waffenerzeugung (mit Ausnahme einer Fabrik) zum wirtschaftlichen Gebrauch (Art. 132 Abs. 3) sowie die Schließung aller nicht mehr benötigten Arsenale verbunden mit der Entlassung des Personals (Art. 132 Abs. 4) und die eingeschränkte und überwachte Verwendung der Wiener drahtlosen Großstation sowie das Verbot der Errichtung einer weiteren (Art. 143). Abweichende Fristen gab es im Abschnitt für die Luftfahrt: Bereits mit Inkrafttreten des Vertrags war das gesamte militärische und Marine-LuftfahrzeugMaterial auszuliefern (Art. 148 Abs. 1); ${ }^{75}$ die Demobilisierung hatte innerhalb von zwei Monaten zu erfolgen. Innerhalb von sechs Monaten blieb die Erzeugung, Ein- und Ausfuhr von Luftfahrzeugen und Luftfahrzeugmotoren, auch in Teilen, auf österreichischem Gebiet verboten (Art. 147); bis zur völligen Räumung war den Flugzeugen der alliierten und assoziierten Mächte (AAM) freie Fahrt sowie Durchfahrtsund Landungsfreiheit zu gewähren (Art. 146). Alle Fristen waren jeweils ab Inkrafttreten des VSG zu berechnen.

Art. 151, der die Mitwirkungspflicht der österreichischen Regierung festlegte, hatte bereits früh Anlass zu Unstimmigkeiten zwischen Österreich und den Überwachungsausschüssen gegeben, nachdem die Botschafterkonferenz am 14. Februar 1920 die vorzeitige Entsendung der Ausschüsse beschlossen hatte. Gegen diese vorzeitige Entsendung (und Inanspruchnahme der vertraglichen Rechte) bestanden Vorbehalte vonseiten Österreichs, das sich auf den Standpunkt stellte, die Entsendung könne nur zu vorbereitenden Tä-

\footnotetext{
${ }^{75}$ Alle Kriegsschiffe und Unterseeboote wurden ebenfalls mit Inkrafttreten als ausgeliefert erklärt (Art. 136). 76 FrEISE, Kommissionen 60.
}

tigkeiten berechtigen. ${ }^{76}$ Diese Anfangsschwierigkeiten, weitere kleinere Zwischenfälle, ${ }^{77}$ und die Uneinigkeit der Ausschussmitglieder untereinander sollten in weiterer Folge eine Verzögerung ihrer Tätigkeit nach sich ziehen. ${ }^{78}$

Die Zusammensetzung der Interalliierten Überwachungsausschüsse hatte nach dem gleichen Grundmuster zu erfolgen: Sie setzten sich ausschließlich aus von den AAHM ernannten Mitgliedern zusammen, als deren Vertreter sie in den betreffenden Angelegenheiten fungierten. Österreich war in den Ausschüssen durch einen „Beauftragten" vertreten, dem eine rein passive, botenähnliche Rolle zugedacht war, die in Art. 151 Abs. 2 mit dem Entgegennehmen von Mitteilungen und der Beschaffung und Übergabe aller vom Ausschuss verlangten Schriftstücke umschrieben wurde. Als Sitz der Dienststellen war in Art. 150 Wien festgelegt worden, wobei sich die Ausschüsse, auch in Form von Unterausschüssen und Beauftragten, im gesamten Bundesgebiet frei bewegen durften. Unterhalt und Kosten hatte Österreich zu tragen (Art. 151 Abs. 2). Angesichts ihrer Zusammensetzung handelte es sich bei den Überwachungsausschüssen um gemeinsame internationale Organe der AAHM, die mit bestimmten durch den VSG festgelegten Aufgaben betraut waren. Hervorzuheben ist auch hier die Rolle der Botschafterkonferenz, die als diplomatische Instanz nicht nur in die Kommunikation eingebunden wurde, sondern auch wesentliche Entscheidungen in der Sache traf. Dies erscheint insofern von Interesse, als ihre Tätigkeit nicht auf die Regelung des Staatsvertrags zurückgeht, der ausdrücklich die alleinige Vertretungsbefugnis der Ausschüsse vorsah.

Eine genauere sachliche Umschreibung der jeweiligen Überwachungspflichten erfolgte für jeden Ausschuss in Art. 153 bis 155. Daneben war

\footnotetext{
77 Dies betraf insbesondere die Tätigkeit des Luftfahrtüberwachungsausschusses, siehe dazu noch unten sowie FREISE, Kommissionen 83.

78 Ebd. 61.
} 
für jeden Ausschuss ausdrücklich die Entgegennahme der Auskünfte der österreichischen Regierung, die einer umfassenden Auskunfts- und Mitteilungspflicht unterlag, normiert.

Der Heeresüberwachungsausschuss (HÜA) hatte gemäß Art. 153 Abs. 2 die Ablieferung von Waffen, Munition, Kriegsgerät, Werkzeug für Kriegsfabrikationen entgegenzunehmen, die Orte, wo diese Ablieferung stattzufinden hatte, festzusetzen und die durch den gegenwärtigen Vertrag vorgesehenen Zerstörungen, Außergebrauchsetzungen oder Umwandlungen $\mathrm{zu}$ überwachen. Auch hatte er zu entscheiden, was mit den Anlangen oder Arsenalen, die über das zulässige Ausmaß hinausgingen und daher zu schließen oder mit rein wirtschaftlicher Zielsetzung zu versehen waren, zu geschehen hatte (Art. 132 Abs. 5). Organisatorisch unterteilte er sich weiter in das Präsidium und zwei Unterkommissionen, ${ }^{79}$ eine Unterkommission für Organisation und Stände (Durchführung von Kapitel II-IV dieses Abschnitts des VSG) ${ }^{80}$ und die Unterkommission für Bewaffnung und Material (Durchführung von Kapitel V dieses Abschnitts des VSG), deren Tätigkeit in besonderem Maße unvollständig bleiben sollte..$^{81}$ An der Spitze des Präsidiums stand der italienische General Zuccari, ${ }^{82}$ auch die Unterkommission für Bewaffnung und Material stand unter italienischer Leitung; die Unterkommission für Organisation und Stände leitete der

\footnotetext{
${ }^{79}$ Ebd. 63.

${ }^{80}$ Diese Unterkommission konzentrierte sich auf den Aufbau der neuen Wehrmacht, wobei mehrere Artikel des neuen Wehrgesetzes 1920 beanstandet wurden, insbesondere auch in Bezug auf die Frage der Rekrutierung und der Offiziersschulen. Besondere Aufmerksamkeit galt auch der gem. Art. 123 vorgeschriebenen Beschränkung der Sicherheitskräfte, über deren Stand über die Tätigkeitsdauer des Ausschusses hinaus zum Teil bis 1928 Nachweise verlangt wurden. Vgl. ausführlich FREISE, Kommissionen 64-67.

${ }^{81}$ Die Tätigkeit der Unterkommission für Bewaffnung und Material, deren Beschlagnahme des gesamten Materials und Versuch der Neuinventarisierung, führte zu Streitigkeiten um den Begriff des „Kriegsmaterials“, über die Kontrollbefugnis und die Möglichkeit seiner
}

Chef der französischen Militärmission. ${ }^{83}$ Inoffiziell bestand der „Rat des Heeresüberwachungsausschusses", in dem sich die Leiter der nationalen Delegationen abstimmten. ${ }^{84}$ Japan war nur im Präsidium, Großbritannien auch in den Unterausschüssen vertreten; der ursprünglich vorgesehene US-amerikanische Beobachter wurde nie entsendet. 85

Der Marineüberwachungsausschuss (MÜA) hatte gemäß Art. 154 Abs. 1 besonders die Aufgabe, sich auf die Bauwerften zu begeben und den Abbruch der dortigen Schiffe zu überwachen, die Ablieferung der Waffen, der Munition und des Materials für die Seekriegsführung entgegenzunehmen und die vorgesehenen Zerstörungen und Abbrüche zu überwachen, nachdem die österreichisch-ungarische Flotte bereits im Herbst 1918 ausgeliefert worden war. ${ }^{86}$ Er war mit einer Mannschaft zwischen zehn und dreißig Personen bedeutend kleiner als der HÜA und stand ebenfalls unter italienischer Leitung (Vizeadmiral Umberto Cagni, zumeist vertreten durch Unteradmiral Ciro Canciani). ${ }^{87}$ Auch dieser Ausschuss nahm seine Tätigkeit vorzeitig auf, sie stellte sich jedoch wesentlich unproblematischer dar als die des HÜA: ${ }^{88}$ Nach Beantwortung seines Fragebogens durch die Marineabteilung des Militärliquidierungsamtes und entsprechenden Besichtigungen wurden die (wenigen) noch notwendigen Zerstörungen und Materiallieferungen

Umgestaltung zur anderweitigen Nutzung. Vgl. FREISE, Kommissionen 69-72.

82 Ebd. 62.

83 Ebd. 64.

${ }^{84}$ Ebd. 63.

${ }^{85}$ Ebd. 63. Die Gesamtgröße des Ausschusses lag nach dem Eintreffen der ersten Staffel im April 1920 bei 30 Offizieren und 77 Mann, ab Mitte Juli 1920 waren es 72 Offiziere und über 200 Mann.

86 Vgl. FrEISE, Kommissionen 74.

${ }^{87}$ Vgl. ebd. 74.

${ }^{88}$ Aus Sicht des österreichischen Beauftragten sei er ohnehin „gänzlich überflüssig und zwecklos gewesen". 
vorgenommen. ${ }^{89}$ Nach Art. 136 Abs. 3 oblag dem Ausschuss zudem die Auswahl der drei Aufklärungsfahrzeuge, die für die Donau behalten werden durften. Auf Ersuchen der österreichischen Regierung und mit Zustimmung der Botschafterkonferenz wurden schließlich vier Patrouillenboote zugesprochen, die im Mai 1921 in Wien einlangten. ${ }^{90}$ Auch die Überwachung der Wiener Radiostationen wurde zunächst vom MÜA, nach dessen Auflösung vom HÜA durchgeführt. ${ }^{91}$ Die ebenfalls auf den HÜA übertragene Überwachung der noch verbliebenen geringfügigen Materialfragen blieb von diesem jedoch unerledigt. ${ }^{92}$ Der Luftfahrtüberwachungsausschuss (LÜA) schließlich hatte den Bestand des in den Händen der österreichischen Regierung befindlichen Flugzeugmaterials aufzunehmen, die Werkstätten für Flugzeug, Ballons und Luftfahrzeugmotoren, die Fabriken für Waffen, Munition und Sprengstoffe, die von Luftfahrzeugen verwendet werden konnten, zu besichtigen, alle auf österreichischem Boden befindlichen Flugplätze, Hallen, Landungsplätze, Parks und Lager zu besuchen und gegebenenfalls die Verbringung des erwähnten Materials an einen anderen Ort zu veranlassen und es zu übernehmen (Art. 155 Abs. 1). Wie der HÜA gliederte sich der LÜA in ein Präsidium und zwei Unterkommissionen, die Unterkommission für die Erzeugung von Luftfahrmaterial und die Unterkommission für die Heeresund Luftschifffahrt; insgesamt gehörten dem unter der Leitung des französischen Oberst Barrès stehenden Ausschuss zwischen elf und zwanzig Offiziere sowie einundzwanzig Mann an. Für die Durchführung der Vertragsbestimmungen ergab sich eine eigene Herausforderung daraus, dass im Juli 1919, mithin bereits vor Abschluss des

\footnotetext{
${ }^{89} \mathrm{Vgl}$. FREISE, Kommissionen 74-76.

90 Vgl. ebd. 76.

${ }^{91}$ Ebd. 75.

92 Ebd. 77.

${ }_{93}$ Ebd. 78.

94 Ebd. 79.

95 Ebd. $79 f$.
}

VSG, alle österreichischen Flugplatzanlagen und alles Flugmaterial unter bestimmten Auflagen an die neu gegründete Luftfahrwesen-Gesellschaft übertragen worden war. ${ }^{93}$ Die österreichische Regierung verneinte daher die Verfügungsbefugnis des Ausschusses nicht nur in zeitlicher Hinsicht (wie beim HÜA), sondern ganz prinzipiell mit dem Argument, dass es sich bei den betreffenden Gegenständen um Privatvermögen handle. ${ }^{94}$ Schließlich wurde im Juli 1920 die Kommunikation mit dem LÜA einer eigens geschaffenen „Luftfriedenskommission“ unter der Leitung des österreichischen Beauftragten übertragen und die (Rück-)Übertragung des Materials an eine "Staatstreuhandgesellschaft" beschlossen, wobei die Vertragsauflösung mit der Luftfahrgesellschaft erst Ende des Jahres gelang. ${ }^{95}$ Nach dem österreichischen Beitritt zum Völkerbund konnten die Flugplätze in Graz, Wien-Aspern, Klagenfurt und Innsbruck, nicht aber in Wiener Neustadt, für die zivile Luftfahrt beibehalten werden; da Österreich die Frist zur Materialübergabe gem. Art. 147 nicht eingehalten hatte, wurde das dortige Ein- und Ausfuhrverbot zunächst auf unbestimmte Zeit verlängert und erst im Herbst 1922 aufgehoben. ${ }^{96}$ Die endgültige Abschaffung sämtlicher Kontrollvorschriften erfolgte schließlich mit dem Luftschifffahrtsabkommen vom 27. Oktober 1927. ${ }^{97}$

Während der MÜA bereits im August $1920^{98}$ nach gut vier Monaten seine Tätigkeit beendet hatte und seine restliche Aufgaben vom HÜA übernommen wurden, blieben der HÜA und der LÜA bis 20. Februar 1921 bestehen. ${ }^{99}$ Ihre Auflösung erfolgte gegen den Willen Italiens und wurde mit

\footnotetext{
${ }^{96}$ Ebd. 81f.

${ }^{97}$ Ebd. 82.

${ }^{98}$ Die Schlusssitzung fand am 8.8. 1920 statt, vgl. FREISE, Kommissionen 76.

${ }^{99}$ Ebd. 73, 82.
} 
der finanziellen Belastung Österreichs begründet. ${ }^{100}$ Sie kam zu einem Zeitpunkt, als noch zahlreiche Arbeiten durchzuführen waren und überraschte auch die Ausschussmitglieder. ${ }^{101}$ Für die Abwicklung der noch offenen Tätigkeiten wurde ein Liquidationsorgan eingesetzt, dessen Leitung dem bisherigen Leiter der Unterkommission für Stände und Organisation, General Hallier, übertragen wurde.102 Seine Mitgliederanzahl war schwankend und verringerte sich bis zu seiner Auflösung am 31. Jänner 1928 auf sieben Mann. ${ }^{103}$ Wenig überraschend ging die weitere Abrüstung nun noch schlechter voran, sodass, wie es im Begleitbrief zu den Abschlussberichten vorsichtig formuliert wurde, bei Abschluss der Arbeiten, ,,nicht alle Fragen' der österreichischen Abrüstung ,befriedigend geklärt” ${ }^{\prime}$ worden “104 waren. ${ }^{105}$

\section{Kriegsgefangene und Grabstätten (Teil VI, Abschnitt I)}

Wie aus dem Bericht der Friedensdelegation hervorgeht, kam der Frage der Kriegsgefangenen von österreichischer Seite höchste Aufmerksamkeit zu. Während die Monarchie keinerlei Aufzeichnungen zu Zahl und Ort der Kriegsgefangenen geführt hatte, stand die junge Republik von Anfang an unter dem Druck, so rasch wie mög-

\footnotetext{
100 Ebd. 84, 73.

101 Ebd. 73. Vgl. auch HeIDEKING, Areopag 332.

102 FREISE, Kommissionen 73. Am 1. 11. 1923 wurde dieser von seinem Landsmann Oberst Leopold Oudry abgelöst.

103 FREISE, Kommissionen 84f

104 Zit. nach HEIDEKING, Areopag 337.

${ }^{105}$ Vgl. zur Tätigkeit des Liquidationsorgans HeIDEKING, Areopag 332-337.

106 RICHTER, Befreiung 1.

${ }^{107}$ Dieser hatte ab 1915 als stellvertretender Direktor des Informationsbüros für Kriegsgefangene und Vizepräsident des Kriegsgefangenenausschusses des Österreichischen Roten Kreuzes fungiert und verfügte
}

lich eine Heimkehr der über die ganze Welt verstreuten Kriegsgefangenen zu bewirken. ${ }^{106} \mathrm{Be}-$ reits im November 1918 war vom Staatsrat eine Kommission unter der Leitung von Slatin $\mathrm{Pa}-$ scha ${ }^{107}$ zur Kriegsgefangenensache eingerichtet worden, die sich diesbezüglich um die Herstellung einer Verbindung mit den Kriegsgegnern bemühte. ${ }^{108}$ Noch vor Aufnahme der Friedensverhandlungen wurde die "Staatskommission für Kriegsgefangene und Zivilinternierte ${ }^{\prime \prime} 109$ eingesetzt, die aus Vertretern der Angehörigen und Kriegsgefangenenorganisationen bestand. Auch ihr war zunächst wenig Erfolg beschieden, da vonseiten der diplomatischen Vertreter der ausstehende Friedensschluss als Verhandlungsbedingung genannt wurde. Bei den Friedensverhandlungen wurde zwar sogar ein persönliches Erscheinen Slatin Paschas vor dem zuständigen Ausschuss ermöglicht, ${ }^{110}$ der ursprüngliche Entwurf der Friedensbedingungen vom 2. Juni erfuhr jedoch trotz der drängenden Bitten der Delegation ${ }^{111}$ keine wesentliche Abänderung. ${ }^{112}$

Gemäß Art. 161 war zur Organisation der Heimschaffung der österreichischen Kriegsgefangenen und Zivilinternierten, die „,nach Inkrafttreten des gegenwärtigen Vertrages so bald wie möglich stattfinden und mit der größten Beschleunigung" (Art. 160) und nach dem Prinzip der Gegenseitigkeit (Art. 167) zu erfolgen hatte, die Bildung eines Ausschusses vorgesehen. Dieser Ausschuss sollte

aus seiner Zeit in Nordafrika über gute Kontakte zu britischen Adelskreisen. Vgl. SAUER, Slatin.

108 RicHTER, Befreiung 1.

${ }^{109}$ Gesetz vom 3. April 1919 über die Kriegsgefangenen- und Zivilinterniertenfrage StGBl. 214/1920.

110 Vgl. Friedensdelegation, Bericht II, 4. Dies war die einzige Ausnahme von den durchwegs schriftlichen Verhandlungen.

111 Siehe die Note über die Kriegsgefangenen vom 16. 7., Friedensdelegation, Bericht II, 58-60, Antwort auf die Friedensbedingungen vom 20. 7., Friedensdelegation, Bericht II, 136-138.

112 Siehe den vergleichenden Abdruck in Friedensdelegation, Bericht I, 55 . 
aus Vertretern aller AAHM und Österreichs bestehen (Art. 161 Abs. 1). Rechtsstellung (v.a. in Bezug auf die Ausübung des Stimmrechts) und Anzahl der Mitglieder wurden im Vertrag zunächst nicht näher bestimmt, wohl aber die Untergliederung in mehrere Unterausschüsse, die nur aus „Vertretern der beteiligten Macht und Abgeordneten der österreichischen Regierung" (Abs. 2 leg.cit.) zusammengesetzt sein sollten und denen die „Einzelheiten der Heimschaffung" überantwortet wurden. Österreich hatte „den Ausschüssen zur Nachforschung nach Vermißten freien Zutritt zu gestatten, ihnen jede geeignete Beförderungsgelegenheit $\mathrm{zu}$ verschaffen, ihnen Einlaß in die Gefangenenlager, Gefängnisse, Lazarette und alle sonstigen Räumlichkeiten zu gewähren sowie ihnen alle amtlichen oder privaten Urkunden zur Verfügung zu stellen, die ihnen bei ihren Nachforschungen Aufschluß geben können." (Art. 168 Z. 1) Die Republik hatte die Beförderungsmittel und das technische Personal zu organisieren und sämtliche Kosten vom Augenblick der Abbeförderung an zu übernehmen (Art. 163). Darüber hinaus verpflichtete der Vertrag ausdrücklich zur Aufnahme aller heimzuschaffenden Personen (Art. 166 Abs. 1). Gem. Art. 162 war auch nach Übergabe an die österreichischen Behörden (!) (unter Umständen im Zusammenwirken mit den militärischen Behörden und Besatzungsarmeen) für die Rücksendung nach dem Heimatort der Betroffenen, d.h. deren Vorkriegswohnsitz, zu sorgen.

\footnotetext{
${ }^{113}$ RICHTER, Befreiung 1.

114 Ebd.

${ }^{115}$ Vgl. ebd. Siehe auch die Note über die Kriegsgefangenen, in der ausdrücklich um ein Zusammentreten der Kommission spätestens nach Unterzeichnung, nicht erst mit Inkrafttreten des Vertrages ersucht wird, Friedensdelegation, Bericht II, 60 .

116 RICHTER, Befreiung 1.
}

Während die Friedensverhandlungen noch andauerten, war es jedoch gelungen, ab Juni 1919 die Rückkehr der Kriegsgefangenen aus Italien zu organisieren, sodass Ende 1919 bereits mehr als 70.000 Betroffene in Österreich eingetroffen waren. ${ }^{113}$ Auch England begann kurz darauf mit dem Rücktransport; ab dem Spätherbst 1919 setzte auch der Rücktransport von Kriegsgefangenen aus Ägypten, Syrien, Griechenland und mit dänischer Unterstützung - aus Serbien ein. ${ }^{114}$ Für den Ausschuss, der - angesichts des drängenden Wunsches nach baldmöglichster Heimkehr der Kriegsgefangenen - aus österreichischer Sicht zu jenen Organen zählte, deren Einsetzung eher vorverlegt denn verzögert werden sollte, ${ }^{115}$ bzw. dessen zuständigen Unterausschuss verblieb somit im Wesentlichen die Organisation des Rücktransports der Kriegsgefangenen aus Frankreich, der von November bis Februar dauerte, und die große Frage der in Russland befindlichen Soldaten, ${ }^{116}$ von der Österreich im Vergleich zu Deutschland in weitaus größerem Ausmaß betroffen war. ${ }^{117}$ Nachdem bereits am 27. August 1919 auf der Friedenskonferenz die Entscheidung gefallen war, den Ausschuss einzusetzen (wenngleich nur unter Bezugnahme auf den deutschen Vertrag), hielt er vom 29. August 1919 bis 9. März 1920 insgesamt sieben Sitzungen ab. Sowohl für die Rückkehr der Kriegsgefangenen aus Frankreich als auch jener aus Sibirien bestand ein eigener Unterausschuss. ${ }^{118}$ Drei der neun Sitzungen des französischen Unterausschusses, in dem Ös-

\footnotetext{
117 Betroffen waren 130.000 österreichische Militäreinheiten und 30.000 Zivilisten, während sich nur 25.000 bzw. 12.000 Personen deutscher Staatsangehörigkeit dort aufhielten. RICHTER, Befreiung 2. Russland selbst war auf der Pariser Friedenskonferenz nicht vertreten, vgl. m.w.N. MacMiLlan, Paris 63-82.

${ }^{118}$ Vgl. Conférence de la paix, Recueil des actes VI, A. Préparation.
} 
terreich von Baron Eichhoff und Konsul Mayrhauser ${ }^{119}$ vertreten war, ${ }^{120}$ befassten sich mit der Rückkehr der österreichischen Kriegsgefangenen, ${ }^{121}$ die sich zum Teil im Inneren des Landes, zum Teil in den zerstörten Provinzen befanden, wobei ein Teil der in Serbien befindlichen Gefangenen auch im Namen der französischen Regierung zurückgehalten worden waren. ${ }^{122}$ Parallel dazu, im Zeitraum von 2. Dezember bis zum 27. März, tagte auch der zweite Unterausschuss, der ausschließlich aus Vertretern der AAHM bestand. ${ }^{123}$ Die besondere Schwierigkeit bestand darin, dass Russland kein Vertragspartner der Pariser Friedensverträge und nach wie vor kein direkter Verkehr mit Russland möglich war. Österreich gelang es zunächst, eine Mission nach Ostsibirien zu erwirken und schließlich durch die eigenmächtige Teilnahme am Kongress der Liga des Roten Kreuzes im März 1920 einen Beschluss über die internationale Organisation des Heimtransportes zu erreichen. Im Juli 1920 kam es zu einer Einigung mit den ukrainischen und russischen Sowjetrepubliken, woraufhin die gegenseitige Heimbeförderung der Kriegsgefangenen ein-

${ }^{119}$ Beide waren aus dem Staatsamt des Äußeren entsandt worden, Johann Eichhoff als Generalkommissär, Walter Mayrhauser als Sachverständiger (vgl. Friedensdelegation, Bericht I 1). Eichhoff wurde im Anschluss Botschafter in Paris, vgl. NAUTZ, Schüller 125.

${ }^{120}$ Conférence de la paix, Recueil des actes VI, A. Préparation 33.

${ }^{121}$ Conférence de la paix, Recueil des actes VI, A. Préparation 37.

${ }^{122}$ Conférence de la paix, Recueil des actes VI, A. Préparation 37.

${ }^{123}$ Conférence de la paix, Recueil des actes VI, A. Préparation $61 \mathrm{f}$

124 RICHTER, Befreiung 2.

125 Ebd. 2.

${ }^{126} \mathrm{Im}$ Gegenteil: Die Situation Karls führte zu einer Diskussion im Rat der Zehn, als Lloyd George berichtete, dass sich die österreichische Regierung offenbar angesichts der bevorstehenden Abdankung und Verbannung des Kaisers an die britische Mission in Wien gewandt hatte, um Karl und seiner Familie eine sichere Abreise zu ermöglichen; die Schweiz habe sich zwar setzte. ${ }^{124}$ Als die österreichische Staatskommission mit 28. Februar 1922 aufgelöst wurde, war der Heimtransport somit in weiten Teilen abgeschlossen. ${ }^{125}$

\section{Strafbestimmungen (Teil VII)}

Für das ehemalige Staatsoberhaupt der österreichisch-ungarischen Monarchie wurde im VSG kein dem Art. 227 des Versailler Vertrags (VV) entsprechendes Strafverfahren vorgesehen. ${ }^{126}$ Analog zum VV regelte der VSG jedoch auch die Anklage und Auslieferung von Personen, die beschuldigt wurden, "gegen die Gesetze und Gebräuche des Krieges“ verstoßen zu haben. Unabhängig von einer etwaigen Verfolgung durch österreichische Behörden verlieh Art. 173 den AAM das Recht, diese Personen vor ihre Militärgerichte zu bringen. Art. 174 differenziert bei der Zuständigkeit nach Staatsangehörigkeit der Opfer: Waren Staatsangehörige einer AAM betroffen, so konnten diese die Militärgerichtsbarkeit ausüben, waren „die strafbaren Handlungen ge-

zur Gewährung der Durchreise, nicht aber des Aufenthalts bereit erklärt - es sei denn, es gäbe eine Garantie der Alliierten, dass daraus in weiterer Folge keine Schwierigkeiten in Bezug auf seine Auslieferung entstehen würden. Lloyd George selbst sprach sich sogleich für die Garantie aus, um die „occurrence of an awful tragedy“ zu vermeiden; nach kurzer Diskussion kam man überein, dem Wunsch nachzukommen und Balfour wurde beauftragt, sich mit der Britischen Mission in Wien in Verbindung zu setzen und die Schweizer Regierung um Gastfreundschaft für die kaiserliche Familie zu bitten. Sollte diese danach verlangen, könne man garantieren, dass keine Schwierigkeiten entstehen würden. (Obgleich man weiterhin davon ausging, dass der Kaiser, wenn überhaupt, nur vor ein eigens zusammengesetztes internationales Gericht gebracht werden könne; von einer zunächst vorgeschlagenen Verweisung der Angelegenheit an eine Kommission hatte man abgesehen.) - Vgl. FRUS, Vol. VI, Dok. 18, Protokoll v. 12. 3. 1919, Pkt. 1, 332-234. 
gen Staatsangehörige mehrerer alliierter und assoziierter Mächte begangen worden, so werden die Täter vor Militärgerichte gestellt, die sich aus Mitgliedern von Militärgerichten der beteiligten Mächte zusammensetzen" (Art. 174 Abs. 2). ${ }^{127}$ Den Angeklagten wurde gem. Abs. 3 leg.cit. ausdrücklich die freie Wahl ihrer Verteidiger zugesichert. Österreich verpflichtete sich nicht nur zur Auslieferung, sondern in Art. 175 auch dazu, „Urkunden und Auskünfte jeder Art zu liefern, deren Vorlegung zur vollständigen Aufklärung der verfolgten Taten, zur Ermittlung der Schuldigen und zur erschöpfenden Würdigung der Schuldfrage für erforderlich erachtet wird." ${ }^{128}$ Was die Einordnung der auf diese Weise ausgestalteten Militärgerichte als „internationale Tribunale" betrifft, so kann die im Schrifttum geäuBerte Kritik an der einseitigen Ausgestaltung des Nürnberger Tribunals auch hier fruchtbar gemacht werden. ${ }^{129}$

127 Zwar war zu dem Zeitpunkt, als die Idee eines Tribunals zur Bestrafung insbesondere Kaiser Wilhelms II. in Großbritannien und Frankreich Form anzunehmen begann, noch keine ausschließlich alliierte Zusammensetzung festgestanden, jedoch hatte sich eine solche noch vor Beginn der Friedenskonferenz abzuzeichnen begonnen, vgl. RUST, Nachkriegsordnung 83-86.

${ }^{128}$ Die übrigen Nachfolgestaaten hatten dagegen nur allgemein die Verfolgung und Bestrafung ihrer von derartigen Vorwürfen betroffenen Staatsangehörigen sicherzustellen (Art. 176).

${ }^{129}$ Vgl. dazu TOMUSCHAT, Courts and Tribunals Rz 10.

${ }^{130}$ Nach Ansicht des britischen „Committee of Enquiry into Breaches of the Laws of War" ändere jedoch weder die mangelnde ausdrückliche Kodifizierung noch die bisher übliche Praxis der Amnestie etwas am entsprechendem Prinzip: WIGGENHORN, Verliererjustiz 10f.

${ }^{131}$ Am 12. 3. erklärte Robert Lansing, der dieser Kommission vorstand, dem Rat der Zehn, dass man keine Liste von Kriegsverbrechern zusammenstellen würde, da die zuständige Subkommission zu der Auffassung gelangt sei, die Verantwortlichkeit für den Krieg sei nur eine moralische, keine rechtliche; FRUS, Vol. VI, Dok. 18, Protokoll v. 12. 3. 1919, Pkt. 1, 332. Die unterschiedlichen Auffassungen verhinderten schließlich ein einstimmiges Ergebnis der Kommission und schlugen sich in einem Sondervotum der US-amerikanischen Vertreter (abgedruckt in: Conférence de la paix,
Eine solche unmittelbare strafrechtliche Verantwortlichkeit war einerseits im bisher kodifizierten Kriegsrecht nicht vorgesehen ${ }^{130}$ und selbst noch im zuständigen vorbereitenden Gremium der Friedenskonferenz, auf dessen Arbeiten die Bestimmungen zurückgehen, nicht unumstritten. ${ }^{131}$ Andererseits waren (deutsche) Völkerrechtsverletzungen bereits seit dem ersten Kriegsjahr dokumentiert und 1916 die Bestrafung der Verantwortlichen als Kriegsziel deklariert worden. ${ }^{132}$

Während man in Deutschland zuerst gegen die schon bei den Waffenstillstandsverhandlungen als Druckmittel verwendeten Auslieferungsansprüche, nach Bekanntgabe der Friedensbedingungen gegen die Strafbestimmungen Sturm lief und sich als „Ersatzangebot“ um die Einrichtung einer speziellen nationalen Gerichtsbarkeit bemühte ${ }^{133}$, lösten die - in allen Friedensbedingun-

Recueil IV, B. 2: Commission des responsabilités 219230) nieder, in dem sowohl die strafrechtliche Verantwortlichkeit (nicht die politische!) von Staatsoberhäuptern und das Vorliegen einer Rechtsgrundlage für bestimmte Tatbestände verneint wurde. Bereits im Vorfeld war die Frage der Verantwortlichkeit von Wilhelm II. Gegenstand interalliierter wie innerstaatlicher Diskussionen gewesen, nachdem Lloyd George die Parole „Hang the Kaiser“ nach einem positiven Gutachten der britischen Kronjuristen gegen den ursprünglichen Rat der meisten Mitglieder des Kriegskabinetts, darunter zahlreiche der künftigen Konferenzteilnehmer wie Milner, Balfour und Bonar Law, im Wahlkampf aufgegriffen hatte. Pläne zur Schaffung eines Tribunals gab es Ende 1918 hingegen auch in Frankreich; eine Position, die Georges Clémenceau befürwortete und für die er um Unterstützung bei den britischen Verbündeten geworben hatte. Auf der Londoner Konferenz fanden diese Pläne (und das von Lloyd George präsentierte Gutachten) schließlich auch die Zustimmung Italiens und wurden Wilson im Wege eines Telegramms, das den Vorschlag zu einem Auslieferungsgesuch einhielt, zur Kenntnis gebracht; vgl. RusT, Nachkriegsordnung $82 \mathrm{ff}$.

132 WiggenHORN, Verliererjustiz 9-11.

133 Ebd. 11-27. 
gen gleichlautenden und den deutschen entsprechenden - Strafbestimmungen keine vergleichbar heftige Reaktion aus. Die deutschösterreichische Friedensdelegation erklärte unter anderem unter Verweis auf die Gesetze und Gebräuche des Krieges, insbesondere die Haager Ordnung, dass danach keine unmittelbare strafrechtliche Verantwortung Einzelner bestünde und sich die Frage der Strafbarkeit und der Auslieferung allein nach nationalem Recht richten würde, zumal eine zusätzliche Verfolgung gegen den Grundsatz „ne bis in idem “ verstoßen würde. $\mathrm{Zu}$ diesen Einwendungen „allgemeiner Art" käme hinzu, dass eine Auslieferung an ausländische Militärgerichte gegen den „allgemeinen Rechtsgrundsatz" des Rechts auf einen gesetzlichen Richter verstieße und auch nach deutschösterreichischem Recht nicht zulässig wäre. Darüber hinaus bettete die Delegation auch hier ihre Argumente in ihren Standpunkt zur Rechtsnachfolge ein: Abermals wurde das Argument bemüht, eine solche Bestimmung träfe Deutschösterreich trotz des gleichlauteten Wortlauts ungleich härter als Deutschland, denn Deutschösterreich habe sich mit den anderen Nationalstaaten niemals im Krieg befunden. ${ }^{134}$

Auch auf Seiten der AAM konzentrierte man sich in erster Linie auf den deutschen Vertrag. Auf Beschluss des Obersten Rates wurde im November 1919 ein Organisationskomitee gegründet, das die vorbereitenden Arbeiten zur Durchführung der entsprechenden Artikel des Versailler Vertrags übernehmen sollte und in dem die AAHM (mit Ausnahme der Vereinigten Staaten) wie auch Belgien, Polen, Rumänien, der SHS-Staat und die Tschechoslowakei vertreten waren. ${ }^{135} \mathrm{Er}$ gebnis seiner Arbeiten waren der Entwurf einer

\footnotetext{
134 „Ergänzung der Gegenvorschläge“ zu den Friedensbedingungen vom 2.6., Friedensdelegation, Bericht I, 279.

${ }^{135}$ Conférence de la paix, Recueil des actes VI, A. Préparation $213 \mathrm{f}$.

${ }^{136}$ Conférence de la paix, Recueil des actes VI, A. Préparation 214. Bekanntlich kam es letzten Endes nie zu
}

Verfahrensordnung und eine Liste der deutschen Staatsangehörigen, deren Auslieferung begehrt wurde. ${ }^{136}$ Ebenso wenig kam es zu einer Bildung eines gemischten Tribunals gemäß Art. 174 Abs. 2 VSG. Analog zu Deutschland wurde eine strafrechtliche Aufarbeitung durch die nationale Gerichtsbarkeit versucht - mit ähnlichem Ergebnis: Nach dem „Gesetz über die Feststellung und Verfolgung von Pflichtverletzungen militärischer Organe im Krieg“137 vom Dezember 1918 gelangten von 484 anhängigen bis Mitte 1920 nur vier Fälle zur Hauptverhandlung vor dem zuständigen Sondersenat des OGH, von denen drei mit einem Freispruch endeten; nach einer $\mathrm{Zu}-$ ständigkeitsübertragung an die Strafgerichte erster Instanz wurde das Gesetz bereits 1922 vollständig aufgehoben. Gegen elf Personen wurden gem. Art. 173 Abs. 2 von der Tschechoslowakei, Jugoslawien und Italien Auslieferungsanträge gestellt. ${ }^{138}$

\section{Wiedergutmachungen (Teil VIII) und Finanzielle Bestimmungen (Teil IX)}

\subsection{Der Wiedergutmachungsausschuss}

Die Schaffung des Wiedergutmachungsausschusses, bald als "Reparationskommission“ in aller Munde, ging auf das Fehlen einer endgültigen Reparationssumme im Versailler Vertrag zurück. ${ }^{139}$ Sie zählte zu jenen Einrichtungen, die eine gesonderte Anlage (primär bestehend aus Organisations- und Verfahrensvorschriften) er-

einer Auslieferung, es blieb bei den sog. Leipziger Prozessen vor dem deutschen Reichsgericht; zu diesen ausführlich WIGGENHORN, Verliererjustiz.

137 StGBl. 132/1918.

138 Vgl. Ziegerhofer, Kommentar Rz. 27.

139 Ausführlich dazu etwa BUIRETTE, Réparer 15-59. 
hielt und stellte eine der größten vertraglich geschaffenen Einrichtungen dar. Dies ist nicht zuletzt darauf zurückzuführen, dass nicht eine Kommission pro Friedensvertrag vorgesehen, sondern ein- und dieselbe Kommission nach dem deutschen, österreichischen und ungarischen Friedensvertrag eingerichtet wurde. Der VSG und der VT bezogen sich explizit auf die Reparationskommission des VV und sahen für die österreichischen und ungarischen Angelegenheiten lediglich jeweils eine eigene Spezialsektion vor.

Neben ihrer „Hauptaufgabe“, nämlich für die Festsetzung und in weiterer Folge Bezahlung der Reparationssumme zu sorgen, hatte die Reparationskommission noch zahlreiche weitere Funktionen wahrzunehmen. Der Großteil der Kompetenzen der Reparationskommission fand sich in Teil IX über die Wiedergutmachung, weitere Kompetenzen waren jedoch auch in den beiden darauffolgenden Teilen (finanzielle und wirtschaftliche Bestimmungen) vorgesehen. Insgesamt hatte die Kommission eher administrativen als judiziellen Charakter. ${ }^{140}$

Art. 179, Anlage II, § 12 Abs. 2 hielt in Bezug auf die Frage der Wiedergutmachung fest: „Allgemein stehen dem Ausschuß hinsichtlich der Frage der Wiedergutmachung, wie sie im gegenwärtigen Teil behandelt ist, die weitestgehenden Überwachungs- und Ausführungsbefugnisse sowie die Ermächtigung zur Auslegung der Bestimmungen dieses Teiles zu. Der Ausschuß bildet

${ }^{140} \mathrm{Vgl}$. ANONYMUS, International Arbitrations 123. Zur Rechtsnatur vgl. RATHMANNER, Reparationskommission 81-85 sowie BuIRETTE, Réparer 114-120. Das Verhältnis zur Botschafterkonferenz behandelt HEIDEKING, Areopag 44f.

${ }^{141} \mathrm{Im}$ Einzelnen finden sich im 9. Vertragsteil dazu noch folgende Aufgaben und Befugnisse: Art. 179 Abs. 2, Anlage II, § 10: Prüfung der Reparationsansprüche, Art. 179 Abs. 3: Feststellung des österreichischen Anteils, Aufstellung und Kontrolle eines 30-jährigen Zahlungsplans, Art. 179 Abs. 2, 180, Anlage II, § 10: Anhörung der österreichischen Vertreter (nach Billigkeit), Art. 179 Abs. 2, 180: Ausgestaltung der Zah- im Rahmen der Bestimmungen des gegenwärtigen Vertrages die alleinige Vertretung der Gesamtheit der [in ihm vertretenen] alliierten und assoziierten Regierungen, und zwar einer jeden, soweit sie beteiligt ist, zur Empfangnahme, zum Verkauf, zur Verwahrung und zur Verteilung der von Österreich gemäß den Bestimmungen des gegenwärtigen Vertragsteiles für Wiedergutmachung zu leistenden Zahlungen." Die Befugnisse der Reparationskommission wurden im Folgenden noch weiter konkretisiert und erstreckten sich bis hin zur Prüfung des österreichischen Steuersystems ( 12 Abs. 2 VSG) ${ }^{141}$ Darüber hinaus konnte sie gemäß Art. 197 Abs. 1 Ausnahmen vom dem dort normierten Generalpfandrecht gewähren, und bis zum 1. Mai 1921 unterlagen Goldausfuhren durch die österreichische Regierung ihrer Genehmigung.

Auch für die in Bezug auf die im Vertrag gesondert geregelten Spezialfälle zu Rückstellungen waren - mehr oder weniger umfangreiche $-\mathrm{Zu}$ ständigkeiten der Reparationskommission vorgesehen. So oblag ihr die Abwicklung der in Anlage IV angeordneten Naturalrestitution und der Rohstofflieferungen nach Anlage $\mathrm{V}$; gemäß Art. 192 Abs. 2 hatte sie gegebenenfalls über die Bewertung und Anrechnung auf die Wiedergutmachungsschuld bestimmter der in Art. 191 genannten und von Österreich auszufolgenden Gegenstände (wissenschaftliches Material, Kunstgegenstände u.dgl.) aus den besetzten Gebieten und nach Art. 199 Abs. 2 über die Bewertung des

lungsmodalitäten, Art. 181: Festsetzung der Vorauszahlungen, Art. 184: Festsetzung des Verfahrens zur Naturalrestitution, Art. 186: Entgegennahme von Auskünften der österreichischen Regierung, Art. 189 lit. c: Festsetzung bestimmter Anrechnungssummen, Anlage II, §7: Ausgestaltung seiner Organisation und Vorsehen „aller Ausführungsmaßnahmen zur Durchführung seiner Aufgaben“, Anlage II, § 11: Verfahrenshoheit, Anlage II, §§ 15, 19: Annahme und Verwaltung der empfangenen Leistungen, Anlage II, § 17: Anzeige und Empfehlungen bei Nichterfüllung seitens Österreichs. 
aufgrund der Waffenstillstandsvereinbarungen ausgelieferten (nicht restituierten!) nichtmilitärischen Materials zu entscheiden. Hier wurde sie auch im Zusammenwirken mit anderen Organen tätig: Die Reparationskommission hatte die Rückstellung der der Untersuchung des - von ihr selbst zu ernennenden - Dreijuristenkomitees überantworteten Gegenstände nach Art. 195 Abs. 2 und 3 anzuordnen und war für die Restitution und Auslieferung von Schiffen und Flussfahrzeugen gemäß Anlage III ${ }^{142}$ zuständig, wobei ihr auch gemäß Art. 300 Abs. 7 die Entscheidung über die Verwendung der Gesamteinnahmen aus der vorläufigen Schiffsvermietung oblag.

Entscheidende Kompetenzen waren der Reparationskommission zudem in Bezug auf die ebenfalls im VSG im Grundsatz geregelte Liquidation der österreichisch-ungarischen Bank, deren Liquidationskommissäre sie gemäß Art. 206 Pkt. 7 ernannte, und die Auseinandersetzung mit den Nachfolgestaaten übertragen. Diese reichten von Bewertungs- und Aufteilungsentscheidungen ${ }^{143}$

\footnotetext{
142 Siehe dazu noch unten.

${ }^{143}$ Art. 203 Pkt. 1 lit. b und d: Festsetzung und Anrechnung des Anteils der durch Eisenbahnen, Salzbergwerke und andere Vermögen besonders sichergestellten Schulden bzw. Zahlungsverpflichtungen der nichtösterreichischen Nachfolgestaaten der Monarchie, Art. 208 Abs. 4, 5, 6: Bewertung und Anrechnung des mit den Gebieten von den nichtösterreichischen Nachfolgestaaten übernommenen öffentlichen Besitzes und Eigentums, Art. 203 Pkt. 2 lit. a: Verteilung der nicht sichergestellten Schulden anhand der Leistungsfähigkeit der Gebiete der ehemaligen Monarchie, Art. 204: Aufteilung der Schulden bei Durchtrennung eines Verwaltungsbezirks durch die neuen Grenzen, Anlage: Abwicklung der Verteilung der nicht sichergestellten, durch Titres repräsentierten Staatsschuld der Monarchie nach Abzug des ungarischen Teils, Art. 213: Bewertung und Anrechnung österreichischer Forderungen und Rechte auf Wiedergutmachung gegenüber seinen ehemaligen Verbündeten, Art. 224 Z. 1 Festlegung der Höchstmenge von zoll- und beschränkungsfreien Kohlelieferungen aus der Tschechoslowakei und Polen in Ermangelung eines entsprechenden Abkommens; Z. 5 leg.cit.: Entscheidung bei Auslegungsund Ausführungsstreitigkeiten.
}

über weitere Ernennungs- und Genehmigungsbefugnisse $^{144}$ bis hin zur Durchführung. ${ }^{145} \mathrm{Im}$ Clearingverfahren hatte die Reparationskommission gemäß Art. 248 lit. d Abs. 4 die maßgebliche Währung und den Umrechnungskurs für Polen und die Tschechoslowakei festzulegen und entschied in Bezug auf die Staaten, die an der Wiedergutmachung nicht beteiligt waren, über den Einzug anstatt einer direkten Auszahlung von Liquidationserlösen an die Eigentümer (Art. 249).

Österreich hatte die Kosten der Kommission zu tragen und war dazu gehalten, die unmittelbare Durchführung der Beschlüsse der Kommission zu akzeptieren, die „im Rahmen der [ihr] übertragenen Befugnisse [...] sofort vollstreckbar und ohne weitere Förmlichkeit alsbald anwendbar" waren (Art. 179, Anlage II, § 14). Es unterlag einer umfassenden Mitwirkungs- und Auskunftspflicht ${ }^{146}$ und wurde zur Kostentragung angehalten (vgl. Art 186 VSG).

Der VSG enthielt auch vergleichsweise ausführliche Regelungen zu Verfahren und Organisation

${ }^{144}$ Art. 203 Pkt. 1 lit. e: Genehmigung der Umrechnungsbasis für österreichisch-ungarische Kronennoten, Art. 215: Ernennung von Schiedsrichtern in Angelegenheiten der finanziellen Liquidation.

${ }^{145}$ Art. 205 Abs. 2: Kriegsschulden: Entgegennahme der abgestempelten Wertpapiere mit den dazugehörigen Akten; Art. 205 Abs. 5, Anlage: Entgegenahme der abgestempelten Noten (mit den dazu gehörenden Akten) der österreichisch-ungarischen Bank, Ausgabe der Zertifikate und Vernichtung der Noten nach Abschluss der Liquidation, Art. 211: zeitlich begrenzte Einzugsmöglichkeit aller Rechte und Beteiligungen österreichischer Staatsangehöriger an öffentlichen Unternehmen oder Konzessionen auf Gebieten seiner ehemaligen Verbündeten (über die österreichische Regierung) unter Anrechnung auf die Wiedergutmachungsschuld.

${ }^{146}$ Das Protokoll zum VSG präzisierte die Auskunftspflicht gegenüber der Kommission dahingehend, dass gem. $\S 1$ Z. 2 die „Verlautbarung von Fabrikationsgeheimnissen oder anderer vertraulicher Informationen" ausgeschlossen war. 
der Kommission (bis hin zur Festlegung ihres Sitzes in Art. 179, Anlage II, §5), nach denen die Kommission jedoch weitgehende Organisationsund Verfahrenshoheit genoss (insbesondere $\S 7$ und § 11). ${ }^{147}$ In Bezug auf die Zusammensetzung bestimmte $\S 2$ Abs. 1, Anlage II zu Art. 179, dass die fünf AAHM und Belgien jeweils einen Delegierten und Ersatzdelegierten, die „fünf anderen Mächte“, d.h. Griechenland, Polen, Rumänien, der serbisch-kroatisch-slowenische Staat und die Tschechoslowakei, durch einen gemeinsamen Delegierten bzw. Ersatzdelegierten vertreten werden würden. Die Zusammensetzung wurde dadurch verkompliziert, dass gemäß Abs. 2 leg.cit. nicht mehr als fünf Delegierte zur Beratung und Stimmabgabe berechtigt sein sollten. Den AAHM kam mit Ausnahme Japans ein ständiger Sitz zu; die Besetzung des fünften Delegierten bestimmte sich nach dem Sachgebiet bzw. nach dem Versailler Vertrag, der statt des gemeinsamen Delegierten einen serbisch-kroatischslowenischen vorsah, wobei manche Sachverhalte mehrere Sachgebiete betrafen und eine entsprechende Besetzung gerechtfertigt hätten. Zudem musste auch bei der Reparationskommission in Ermangelung der Ratifikation des VSG durch die Vereinigten Staaten eine Lösung - in Form der Teilnahme eines informellen Vertreters - gefunden werden. Die österreichische Sektion, der gemäß Art. 179 Abs. 1 jedoch in der Regel nur beratende Funktion zukam, setzte sich aus Vertretern der vier ständigen Mächte und dem gemeinsamen Delegierten zusammen (Art. 179, Anlage II, § 3 Abs. 2). ${ }^{148}$ Freilich blieben die län-

\footnotetext{
147 Zudem waren die einschlägigen Bestimmungen vor allem in Anlage II enthalten, die mittels einstimmigen Beschlusses auch grundsätzlich abänderbar war (Art. 179, Anlage II, § 22 VSG).

${ }^{148} \mathrm{Vgl}$. genauer zur Zusammensetzung, insbesondere der österreichischen Sektion, RATHMANNER, Reparationskommission 86-88.

149 Siehe ausführlich BUIRETTE, Réparer 105-113.

${ }^{150}$ BuIRETTE, Réparer $145 f$.

${ }^{151}$ Vgl. BANSLEBEN, Liquidation und Rekonstruktion 4f.
}

derspezifischen Spezialsektionen nicht die einzigen Organisationseinheiten der Kommission: Neben dem Generalsekretariat bestanden nicht weniger als sieben allgemeine Dienststellen, jeweils unterstützt von einem eigenen Rat, die sich ihrerseits zum Teil wieder in Sektionen untergliederten. ${ }^{149}$

Noch bevor sich die eigentliche Reparationskommission konstituierte, trat sie auf Initiative von Louis Loucheur bereits am 3. Juli 1919 als „Organisationskomitee“ zusammen. ${ }^{150}$ Auch die Wiener Sektion wurde zunächst als „Organisationskomitee" tätig; sie nahm - auf Ersuchen der österreichischen Regierung - vorzeitig ihre Tätigkeit auf und hielt am 1. Juli 1920 ihre erste Sitzung in Wien unter dem Vorsitz ihres Präsidenten Sir William Goode ab, sollte jedoch schon im Mai 1921 ihren Sitz nach Paris verlegen. ${ }^{151}$ Von der österreichischen Regierung wurde für den Verkehr mit der Reparationskommission im Außenministerium unter der Leitung von Sektionschef Schüller ${ }^{152}$ eine eigene Kommission eingerichtet, die aus Vertretern sämtlicher Ressorts bestand. ${ }^{153}$

Von Beginn an sah sich die Kommission in Bezug auf Österreich weniger mit der - ohnehin an die Lösung des deutschen Reparationsproblems geknüpften - allgemeinen Reparationsverpflichtung Österreichs als mit den im VSG speziell normierten Reparationsforderungen und Rückerstattungen sowie ihren zahlreichen anderen Aufgaben,

152 Der habilitierte Nationalökonom Friedrich SCHÜLLER leitete seit 10.11. 1918 die handelspolitische Sektion im Staatsamt für Äußeres, vgl. NAUTZ, Schüller 9, 13. Als Generalkommissär der deutschösterreichischen Friedensdelegation (Friedensdelegation, Bericht I, 1) hatte er bereits bei den Verhandlungen in Paris den wirtschaftlichen und finanziellen Teil des Vertrags bearbeitet; NAUTZ, Schüller 124.

${ }^{153}$ Neue Freie Presse, Nr. 20046 v. 19. 6. 1920, 1. 
insbesondere im Zusammenhang mit der Liquidation der österreichisch-ungarischen Bank, ${ }^{154}$ konfrontiert. Hinzu kam die schwierige finanzielle Situation des österreichischen Staates, der nach wie vor auf Kredite für Lebensmittellieferungen angewiesen war. ${ }^{155}$ So sollten schon bald ihre Durchführungs-, Überwachungs- und Kontrollfunktionen zugunsten einer vermittelnden Rolle im finanziellen (Wieder)Aufbau der Republik in den Hintergrund treten. ${ }^{156}$ Obgleich im Vertrag selbst (Art. 179, Anlage II, § 23) die Bestandsdauer der Kommission festgelegt worden war (bis zur Bezahlung und Verteilung aller von Österreich geschuldeten Summen), wurden die Beziehungen der Reparationskommission zu Österreich unabhängig davon auf der Haager Konferenz 1930 beendet. ${ }^{157}$

\subsection{Die Liquidatoren (Teil IX)}

Durch den VSG wurde die Liquidation der österreichisch-ungarischen Bank unter der Ägide der Reparationskommission festgelegt; die zentrale Bestimmung des Art. 306 übertrug in Abs. 7 die Durchführung der Liquidation innerhalb der vorgesehen Fristen den von der Reparationskommission ernannten „Kommissären“. 158

154 Vgl. Neue Freie Presse, Nr. 20046 v. 19. 6. 1920, 1.

155 So hatte sich etwa bereits 1919 das Organisationskomitee mit der dringenden Bitte um Unterstützung der Lebensmittelversorgung auseinandersetzen müssen, vgl. BuiRETTE, Réparer 153-155.

${ }^{156}$ Vgl. zusammenfassend dazu m.w.N. RATHMANNER, Reparationskommission 94f. Zur Rolle der Reparationskommission vor der Genfer Sanierung vgl. PIETRI, Reconstruction financière 25-39. Treffend auch SCHENK, Abrechnungsschuldverschreibungen 7:

„Nun ist allerdings diese Aktivpost der Sieger gegen Österreich etwas dubios geworden, und die Reparationskommission, deren Aufgabe es eigentlich gewesen wäre, die Schäden der Sieger zu reparieren, trachtet jetzt mit wenig Erfolg danach, daß sie Österreich repariert."

${ }^{157}$ RATHMANNER, Reparationskommission 95f.

${ }^{158} \mathrm{Im}$ Allgemeinen wurden sie nur selten als solche bzw. als „Liquidationskommissäre“, sondern schlicht
Im Gegensatz zu einigen anderen Einrichtungen wurden die Liquidationskommissäre erst nach Ratifizierung des Friedensvertrages ernannt. Im Vorfeld war zum einen die Bestellung eines englischen Kommissärs vermeldet ${ }^{159}$ und zum anderen vermutet worden, dass mehrere Vertreter der Ententestaaten und der neutralen Staaten sowie ein rumänischer und italienischer Delegierter dafür in Betracht kämen. ${ }^{160}$ Die Ernennung der drei Kommissäre, des amerikanischen Anwalts und Liquidationsexperten ${ }^{161}$ Edmund Whitman, des vormaligen italienischen Regierungskommissärs Giuseppe Luxardo und des rumänischen Delegierten Alexander Zeuceanu erfolgte schließlich im August 1920 kurz vor Beginn der Liquidation im September ${ }^{162}$ und wurde am 31. August in der Sitzung des Generalrats der Notenbank mitgeteilt. ${ }^{163}$ Nach dem Rücktritt des amerikanischen Delegierten trat Gilbert Monès de Pujol dessen Nachfolge an. ${ }^{164}$

Inhaltlich hatten diese nicht nur die Vorschriften des Art. 206 samt Anlage, sondern grundsätzlich auch „die Statuten und im Allgemeinen die geltenden auf den Betrieb der Bank bezughabenden Vorschriften zu beobachten." Im Falle von „Meinungsverschiedenheiten" über die Auslegung sowohl der Vorschriften des VSG als auch der in

als „Liquidatoren“ der österreichisch-ungarischen Bank bezeichnet.

${ }^{159}$ Genannt wurde die Bestellung eines Dr. Harvey, vgl. NEISSER, Volkswirtschaftliche Chronik 165.

160 Salzburger Volksblatt, Nr. 153 v. 8. 7. 1920, 7; Innsbrucker Nachrichten, Nr. 125 v. 7. 7. 1920, 11.

161 Neues Wiener Tagblatt, Nr. 223 v. 14. 8. 1920, 10.

162 KERNBAUER, Währungspolitik 27. Der Autor nennt den 1. 9. als Zeitpunkt des Liquidationsbeginns, den Zeitpunkt der ersten offiziellen Kontaktaufnahme der Liquidationskommissäre mit der Notenbank (siehe WEISSENBACHER, Liquidation 61). Der VSG (Art. 206 Abs. 6) hatte - ebenso wie rückwirkend der Vertrag von Trianon (Art. 189 Abs. 6) - den der Unterzeichnung des VSG folgenden Tag, d.h. 11. 9. 1919, festgelegt.

163 Deutsches Volksblatt, Nr. 11369 v. 1. 9. 1920, 8.

${ }^{164}$ KERNBAUER, Währungspolitik 426. 
den Bankstatuten selbst festgelegten Liquidationsnormen war die Reparationskommission oder ein von ihr zu diesem Zweck ernannter Schiedsrichter als Appellations- und zugleich letzte Instanz zur Entscheidung berufen (Art. 206 Z. 7).

Die von den Liquidatoren übernommene Aufgabe war geprägt von „zahllosen Schwierigkeiten tatsächlicher und juristischer Art", 165 die durch ihre vergleichsweise späte Ernennung noch verschärft worden waren und durch die ablehnende Haltung der österreichischen Regierung nicht gerade erleichtert wurden. ${ }^{166}$ Entgegen der Hoffnungen (und Proteste) der Leitung der Notenbank auf einen Erhalt der Währungsgemeinschaft zumindest zwischen der Tschechoslowakei, Österreich und Ungarn war die Währungstrennung bereits um den Jahreswechsel 1918/1919 in vollem Gange gewesen. ${ }^{167}$ Die Leitung der Bank hatte trotz Bestätigung der Liquidation durch den VSG im Herbst 1919 die laufende Tätigkeit, auch die Notenausgabe, bis zur Unterzeichnung des Vertrags von Trianon im Juni 1920 (der an dem im VSG festgesetztem Datum festhielt) aufrecht erhalten. ${ }^{168}$ Die Schwierigkeiten juristischer Art begannen schon mit den inhaltlichen Vorgaben (so knapp sie auch scheinen mochten), da die Regelungen des Art. 206, „der zu den verwickeltsten und unklarsten des

165 Vortrag des Liquidationskommissärs Monès de Pujol, Bericht in der Wiener Zeitung, Nr. 103 v. 5. 5. 1921, 7.

166 Vgl. WEISSENBACHER, Liquidation 59-64.

167 Vgl. KERNBAUER, Währungspolitik 25f. Eine Schilderung des Ablaufs der Währungstrennung nach Nationalstaaten findet sich bei WEISSENBACHER, Liquidation 38-57.

168 Vgl. WeISSENBACHER, Liquidation 59. Noch am 31. 8. 1919 gelangten in der Generalratssitzung - abgesehen von der Bekanntgabe der Liquidatoren - „nur Gegenstände der laufenden Verwaltung zur Erledigung.“ (Deutsches Volksblatt, Nr. 11369 v. 1. 9. 1920, 8). Auch nach Tätigkeitsaufnahme der Liquidatoren stand die Bankleitung einem allzu raschen, „forcierten Abbruch der Tätigkeit der österreichisch-ungarischen Bank“ ablehnend gegenüber, vgl. FüLÖP, Notenbank 1. Letzten ganzen Vertrages [...] gehörte" ${ }^{\prime 169}$ sich zum Teil als undurchführbar herausstellten oder Unklarheit darüber herrschte, wie sie am besten mit den Statuten in Einklang zu bringen waren. ${ }^{170}$ Die Interpretationsschwierigkeiten führten $\mathrm{zu}$ einem Ruf nach „authentischer Interpretation" (lies: einer verbindlichen freien Interpretation) ${ }^{171}$ und Verhandlungen vor der Reparationskommission, ${ }^{172}$ die entschied, die Angelegenheiten im Wege einer internationalen Konferenzen unter Leitung der Liquidatoren zu behandeln, an der neben Vertretern der Reparationskommission insbesondere auch Vertreter der Gläubiger, insbesondere der Nachfolgestaaten, der Bank selbst sowie anderer interessierter Banken und der österreichischen und ungarischen Regierung teilnehmen sollten. Es sollte nicht die einzige bleiben: Es folgten mehrere Konferenzen mit den Nachfolgestaaten, von denen insbesondere jene Konferenz im Frühjahr 1922, bei der man sich auf die endgültige Aufteilung der Aktiven und Passiven einigte, zu erwähnen ist. ${ }^{173}$ Die Ausschüttung der Aktiven, die - mit Ausnahme einiger noch offener Prozesse - das Ende der Liquidationsschulden markierte, erfolgte Mitte Juli 1924. ${ }^{174}$ Bereits im Jahr davor war die Schlussbilanz der österreichisch-ungarischen Bank beschlossen und das Vermögen auf

Endes blieb die österreichisch-ungarische Bank bis zum Jahresende 1922 Notenbank, vgl. KERNBAUER, Währungspolitik 27.

169 Ebd. 26.

170 Ebd. 27.

${ }^{171}$ Vgl. Neues Wiener Tagblatt, Nr. 341 v. 12. 12. 1920, 14.

172 Diese fanden im Dezember 1920 und unter Beteiligung nicht nur der Liquidatoren, sondern auch von Vertretern der österreichischen Regierung und der Leitung der Notenbank statt. NEISSER, Volkswirtschaftliche Chronik 415.

173 KeRnBAUER, Währungspolitik 27.

174 Reichspost, Nr. 201 v. 22. 7. 1922, 10. 
die im Dezember 1922 neu gegründete Nationalbank ${ }^{175}$ übertragen worden. ${ }^{176}$

\subsection{Das „Dreijuristenkomitee“ (Teil VIII, Abschnitt II)}

Gemäß Art. 195 VSG hatte die Prüfung einer etwaigen Restitutionspflicht in Bezug auf die (in den Anhängen aufgezählten) Kunstgegenstände und Urkunden gegenüber Italien (Abs. 1 und 2 leg.cit., Anlage I) sowie gegenüber Belgien (Abs. 3 leg.cit., Anlage II), Polen (Abs. 3 leg.cit., Anlage III) und der Tschechoslowakei (Abs. 3 leg.cit., Anlage IV) durch ein Komitee von drei Juristen zu erfolgen, das von der Reparationskommission zu ernennen war. Dem Komitee selbst oblag dabei nur die Feststellung, ob die sich nunmehr im Besitz der Republik Österreich befindlichen Gegenstände im 18. Jahrhundert rechtswidrig erworben bzw. verbracht worden waren. ${ }^{177}$ Der binnen Jahresfrist ab Inkrafttreten zu erstattende Bericht bildete die Grundlage der Anordnungsbefugnis zur Restitution, die bei der Reparationskommmission verblieb und zu deren Anerkennung sich die jeweiligen Streitparteien im VSG ausdrücklich verpflichtet hatten ${ }^{178: ~ „ S o ~}$ lag in der Sache, wenn auch nicht der Form nach,

\footnotetext{
175 Ausführlich zur Entstehungsgeschichte der österreichischen Nationalbank KERNBAUER, Zwischenkriegszeit 61-78.

${ }^{176}$ Die letzte Vollversammlung der Aktionäre fand am 27. 7. 1923 statt, vgl. z.B. Neue Freie Presse, Nr. 21150 v. 28. 6. 1923.

177 Vgl. auch Commission des Réparations, Annexe 4.

178 Commission des Réparations, Annexe 4.

179 „Thus in substance, though not in form, the ultimate decision of the matters in the dispute rested with the Jurists' Committee, the Commission being the executive authority for the enforcement of the judgement." ANONYMUS, International Arbitrations 125.

${ }^{180}$ Commission des Réparations, Annexe 3. Als Sekretär fungierte H. Valentino. Vgl. auch DE VISSCHER, Protection Internationale 276.

181 LHOTSKY, Wiener Sammlungen 638.

182 Ebd. 634f. Ausführlich zur Einigung mit Italien auch HugUENIN-BERGENAT, Kulturgüter 123-130.
}

die Letztentscheidung über die strittigen Angelegenheiten beim Juristenkomitee, nachdem die Kommission die ausführende Autorität für die Durchsetzung des Urteils darstellte. ${ }^{179}$

In Ausführung des Art. 195 übertrug somit die Reparationskommission die Entscheidung über alle Fragen bezüglich der Restitution von Kunstgegenständen, die durch den Vertrag von St. Germain speziell zugeordnet wurden, dem „Dreijuristenkomitee" (Entscheidung Nr. 901) und ernannte in weiterer Folge (Entscheidung Nr. 948) den New Yorker Anwalt Hugh A. Bayne (USA), Jaques Lyon, Anwalt am Cour de Paris (FR) und K. Fischer-Williams (GB) als Mitglieder. ${ }^{180}$ Den Vorsitz führte Jaques LYON. ${ }^{181}$

Allerdings gelangten nicht alle im VSG genannten Ansprüche zur Entscheidung durch das Komitee. Bereits vor Inkrafttreten des Vertrags schlossen Österreich und Italien am 4. Mai 1920 ein Sonderabkommen über die betreffenden Gegenstände, ${ }^{182}$ während Polen auf die Geltendmachung seiner Ansprüche verzichtete. ${ }^{183}$ Auch ein Teil der belgischen ${ }^{184}$ und tschechoslowakischen ${ }^{185}$ Ansprüche wurde zwar vor dem Komitee, allerdings gütlich im Vergleichswege erledigt. ${ }^{186}$ Somit verblieben zur Entscheidung des

183 LHOTSKY, Wiener Sammlungen 639; HUGUENIN-BERGENAT, Kulturgüter 164.

${ }^{184}$ Die Einigung kam erst am 30. 3. 1922 zustande, da in Übereinstimmung mit den belgischen und österreichischen Vertretern die Behandlung dieser Ansprüche auf den Zeitraum nach der Entscheidung über die Forderungen nach dem Triptychon des Hl. Ildefonso von Rubens und den Schatz des Ordens vom Goldenen Vlies verschoben worden war. Vgl. Réparations, Annexe 4; HuguENIN-BERGENAT, Kulturgüter 160; siehe auch LHOTSKY, Wiener Sammlungen 635-7.

185 Dies betraf alle in Anlage IV genannten Objekte mit Ausnahme der Kunstgegenstände. Hier war die Einigung bereits im Vorhinein, am 1. 10. 1920, erfolgt. Vg1. HuguenIN-BERGENAT, Kulturgüter 141 Anm. 671.

186 ANONYMUS, International Arbitrations 125. 
Komitees die Ansprüche Belgiens auf das Triptychon des $\mathrm{Hl}$. Ildefonso von Rubens und den Schatz des Ordens vom Goldenen Vlies sowie die tschechoslowakischen Ansprüche auf die in Anlage IV Z. 2 genannten Kunstgegenstände, wobei letztere und der Anspruch auf das Triptychon ähnliche Rechtsfragen aufwarfen. ${ }^{187}$

Das Verfahren gestaltete sich jeweils analog und entsprechend „,what may be called the usual procedure in international ligitation", wonach den Parteien zunächst Gelegenheit zur Darlegung ihrer Standpunkte im Wege eines Schriftwechsels gegeben wurde ${ }^{188}$ und im Anschluss eine mündliche Verhandlung in Paris stattfand. ${ }^{189}$ Zunächst erfolgte die Auseinandersetzung mit Belgien: Die mündlichen Verhandlungen in Paris fanden vom 11. bis 13. Juli 1921 statt, wobei es im Anschluss erneut die Möglichkeit zur Ergänzung gab; der Bericht an die Reparationskommission datiert vom 21. Oktober desselben Jahres. ${ }^{190}$ Die Entscheidung der Reparationskommission folgte im Jänner 1922. ${ }^{191}$ Daraufhin wurde im Februar das Verfahren über die tschechoslowakischen Ansprüche eingeleitet, das nach mündlichen Verhandlungen von 27. bis 29. März in den Bericht

187 Ebd. 125-127.

188 Vonseiten Österreichs wurden die vorbereitenden Arbeiten vom Unterrichtsamt geleitet. Neues Wiener Tagblatt. Nr. 42 v. 11. 2. 1922, 6.

189 ANONYMUS, International Arbitrations 125; siehe auch HuguENIN-BERGENEAT, Kulturgüter 117.

190 Bericht, Annex 1141 4f., 52; siehe auch HugUENINBERGENAT, Kulturgüter 160 Anm. 437.

${ }^{191}$ Neues Wiener Tagblatt, Nr. 42 v. 11. 2. 1922, 6; O., International Arbitrations 128 Anm. 1.

192 Bereits im August war die Verzögerung erwartet worden, vgl. Neues Wiener Tagblatt, Nr. 233 v. 25. 8. 1922, 5.

${ }^{193}$ Huguenin-BergenAt, Kulturgüter 141f.; Prager Tagblatt, Nr. 302 v. 28. 12. 1922, 3; Neues Wiener Tagblatt, Nr. 25 v. 27. 1. 1928, 5.

194 ANONYMUS., International Arbitrations 129. Was den Schatz des Ordens vom Goldenen Vlies anlangt, ist allerdings anzumerken, dass der Erfolg Österreichs im Verneinen des belgischen Anspruchs bestand, da, wie das Komitee hervorhob, die Republik Österreich des Komitees vom 23. August 1922 und die (späte) ${ }^{192}$ Entscheidung der Reparationskommission vom 22. Dezember 1922 mündete. ${ }^{193}$ In allen Fällen erfolgte die Entscheidung des Komitees einstimmig und zugunsten Österreichs. ${ }^{194}$

Wenig überraschend wurden die Entscheidungen des Komitees, das im Ruf „absoluter Fairneß " stand, dessen Vorsitzender deutsch sprach und "sehr große Geduld“ an den Tag legte, ${ }^{195}$ in Österreich wohlwollend zur Kenntnis genommen. Inhaltlich finden sich in der Literatur zum Teil sehr kritische Stimmen, die sich auf das zur Beurteilung herangezogene Recht ${ }^{196}$ und dessen Auslegung bezogen oder den Mitgliedern als Westeuropäern und Amerikanern mangelnde Vertrautheit mit den „rechtlichen und historischen Feinheiten" vorwarfen. ${ }^{197}$ Allerdings ist Huguenin-Bergenat darin beizupflichten, dass die Einrichtung eines Komitees, das nach rein rechtlichem Maßstab ${ }^{198}$ entschied, angesichts des Verhältnisses der Nachfolgestaaten untereinander durchaus als „gute und vernünftige Lösung“ angesehen werden kann. ${ }^{199}$ Auch die Durchfüh-

keine Besitzansprüche geltend gemacht hatte und ohne Beteiligung des Ordens und seiner Vertreter auch keine endgültige Entscheidung darüber getroffen hätte werden können. Vgl. Commission des Réparations, Annexe 52. Heute befindet er sich in der Schatzkammer des Kunsthistorischen Museums in Wien. Vgl. Huguenin-Bergenat, Kulturgüter 164 Anm. 755.

${ }^{195}$ LHOTSKY, Wiener Sammlungen 638.

196 Nämlich das zum Zeitpunkte der Verbringung geltende - nach Ansicht eines anderen Autors war bereits damit das Ergebnis im Falle des Triptychons und der tschechoslowakischen Ansprüche bei einem Vorgehen nicht „as statesmen or diplomatists [sondern] as lawyers" schlichtweg unvermeidlich, siehe ANONYMUS, International Arbitrations 126.

197 Huguenin-BergenAt, Kulturgüter 161.

198 Eine solchen hatte im Vorfeld auch die österreichische Delegation gefordert, vgl. LHOTSKY, Wiener Sammlungen 630.

199 Huguenin-BergenAt, Kulturgüter 185. 
rung des Verfahrens, in dem die Parteien ausführlich Stellung nehmen und gleichberechtigt auftreten konnten, ${ }^{200}$ erscheint beispielhaft.

\section{Wirtschaftliche Bestimmungen (Teil X)}

\subsection{Gemischter Schiedsgerichtshof (Abschnitt VI)}

Als Ausgangspunkt der "modernen“ internationalen Schiedsgerichtsbarkeit wird regelmäßig201 der 1794 zwischen den USA und Großbritannien abgeschlossene Jay-Vertrag genannt, in dem drei "Mixed Claims Commissions" als gemeinsame Organe der beiden Vertragspartner zur Entscheidung strittiger Fragen vorgesehen waren. ${ }^{202}$ Historisch waren die "Tribunaux Mixtes", die "Gemischten Schiedsgerichtshöfe", die Nachfolger solcher "Mixed Claims Commissions", die ihrerseits zum Teil ${ }^{203}$ den Schiedsspruch Einzelner abgelöst hatten. ${ }^{204}$ Die Besonderheit dieser Gemischten Schiedsgerichtshöfe, der sie auch ihren Namen verdankten, lag darin, dass sie sowohl Staaten als auch Einzelnen als Parteien offen standen. ${ }^{205}$

Im VSG tritt die Bedeutung der internationalen Schiedsgerichtsbarkeit deutlich zu Tage; die Kernbestimmung stellt Art. 256 zu den Gemischten Schiedsgerichtshöfen dar: Dort finden sich

\footnotetext{
200 Dass diese Gleichberechtigung bereits durch die Einrichtung des Komitees in Art. 195 angelegt war, hebt auch LHOTSY, Wiener Sammlungen 633, hervor.

${ }^{201}$ Die Idee und Funktion der Schiedsgerichtsbarkeit kann bis ins Altertum zurückverfolgt werden. Der angeblich älteste Fall stammt aus der Zeit um 2600 v. Chr. Auch im antiken Griechenland war die Schiedsgerichtsbarkeit verbreitet - vgl. den historischen kurzen Abriss bei KNEISEL, Schiedsgerichtsbarkeit 1-7. Zur „Wiedergeburt“ der internationalen Schiedsgerichtsbarkeit im "Britischen Zeitalter" siehe auch GREWE, Epochs 517-524.

202 ZIEGLER, Jay-Treaty Rz 6.
}

grundlegende organisations- und verfahrensrechtliche Bestimmungen, die durch eine Anlage ergänzt werden. Gem. lit. d leg.cit. war ein jeder der Gemischten Schiedsgerichte selbst zum Erlass seiner Verfahrensordnung ermächtigt, ${ }^{206}$ die nach § 2 der Anlage „nach Grundsätzen der Gerechtigkeit und Billigkeit" zu erfolgen hatte. Weitere verfahrensrechtliche Vorgaben fanden sich auch in der Anlage zu Art. 248 betreffend das Clearingverfahren, nachdem die Gemischten Schiedsgerichtshöfe einen Teil der Organisationsstruktur des „äußeren“ Clearingverfahrens zur zwischenstaatlichen Abrechnung bildeten. ${ }^{207}$

Was die in Art. 256 lit. a, c und § 1 der Anlage geregelte Zusammensetzung anlangt, so hatte diese insofern auf klassische Weise zu erfolgen, als ein jeder der Gemischten Schiedsgerichtshöfe aus drei Mitgliedern bestand, von denen zwei binnen Monatsfrist von den beteiligten Regierungen ernannt werden mussten; die Ernennung des Vorsitzenden hatte in Übereinstimmung zwischen ihnen zu erfolgen, wodurch ein Element der Neutralität hinzukam. Sollten sich die Regierungen auf die Person des Vorsitzenden nicht einigen können, ging das Ernennungsrecht für diesen und zwei weitere Personen als Stellvertreter auf den Völkerbundrat (bis zu dessen Errichtung auf Gustav Ador, den Präsidenten des IKRK ${ }^{208}$ ) über und die Auswahl beschränkte sich auf den Kreis der Staatsangehörigen der im Krieg neutral

${ }^{203}$ Nichtsdestotrotz finden sich im VSG auch zahlreiche Beispiele solcher Schiedsklauseln, deren Darstellung im Einzelnen den Rahmen dieser Arbeit sprengen würde.

${ }^{204}$ Die Unparteilichkeit der Mitglieder der Mixed Claims Commissions vorausgesetzt, findet sich jedoch kein qualitativer Unterschied zwischen diesen Einrichtungen und den Mixed Tribunals. Vgl. DoLzER, Mixed Claims Commissions Rz 2.

${ }^{205}$ Vgl. De AuER, Competency 17.

${ }^{206}$ Ein Abdruck der einzelnen Verfahrensordnungen findet sich in der 1921-1930 erschienenen offiziellen Entscheidungssammlung der gemischten Schiedsgerichte (Tribunaux arbitraux mixtes, Recueil).

207 Vgl. PILS, Kommentar Rz. 48.

208 WALTER, Gustave Ador. 
gebliebenen Staaten. Bei Säumigkeit bei der Ernennung einer der beiden übrigen Mitglieder hatte die gegnerische Regierung das fehlende dritte Mitglied unter den beiden als Stellvertreter nominierten Personen auszuwählen. Nach diesem Verfahren hatte auch die Ernennung eines neuen Mitglieds (etwa im Todesfall oder bei Rücktritt) zu erfolgen. Sollte es die Zahl der Verfahren erforderlich machen, konnten die Schiedsgerichtshöfe nach denselben Grundsätzen um weitere Mitglieder ergänzt und in mehrere Abteilungen gegliedert werden. Nach lit. d und e leg.cit. war die Bezahlung der Mitglieder entsprechend der Ernennungsbefugnis geregelt: Jede Regierung kam für die Bezüge des von ihr ernannten Mitglieds auf, die Höhe der Bezüge des Vorsitzenden wurde aufgrund besonderer Vereinbarung bestimmt und von beiden Regierungen jeweils zur Hälfte finanziert. Auch die gemeinsamen Ausgaben des Gerichts wurden 50:50 aufgeteilt. Allerdings hatte ein jeder der Schiedsge-

${ }^{209}$ Art. 249 lit. e: Feststellung der Höhe der Entschädigung für Staatsbürger der AAM, die durch die in der Anlage näher bezeichneten außerordentlichen Kriegsmaßnahmen und Übertragungsanordnungen betroffen waren; Art. 249 lit. i: Überprüfung der - an die Eigentümer zu zahlenden - Liquidationserlöse der Nachfolgestaaten und der Staaten, die an Österreichs Wiedergutmachungen keinen Anteil haben und ggf. Festlegung einer Entschädigung; Art. 251 lit. b: Entschädigung für Verträge zwischen Feinden, die auf Verlangen einer der AAM, denen eine Vertragspartei angehört, aufrechterhalten wurden, wenn diese Aufrechterhaltung aus wirtschaftlicher Sicht für eine Partei einen erheblichen Nachteil mit sich bringt; Art. 252 lit. c-e: Festlegung der Entschädigung, falls die Wiederherstellung des durch Vollstreckungsmaßnahmen oder Vertragsaufhebung beeinträchtigten Rechtszustandes „ungerecht oder unmöglich ist“; Art. 254 Abs. 1 und 4: Schadenersatz für die Verletzung des Rechts auf rechtliches Gehör eines Staatsangehörigen der AAM durch Gerichtsentscheidungen und Exekutionsmaßnahmen während des Krieges.

${ }^{210}$ Gemäß Art. 249 lit. e und lit. i, falls die Höhe nicht vom Tribunal jeweils selbst festgestellt wird.

${ }^{211}$ Art. 252 lit. b, c, e: Einsprüche von Staatsangehörigen der AAM gegen Vollstreckungsmaßnahmen, die richtshöfe das Recht, in seiner Verfahrensordnung Kostenersatz für die verlierende Partei vorzusehen; ergänzende Regelungen bestanden in Bezug auf das Clearingverfahren (Art. 248, Anlage, § 20). Im Verfahren konnten sich die beteiligten Regierungen durch Beauftragte vertreten lassen, wobei nur im Clearingverfahren nach Art. 248, § 18 Abs. 1 der Anlage, die Regierungen verpflichtend einen Vertreter $\mathrm{zu}$ ernennen hatten, dem im Namen des Amtes seines Landes die Verfahrenseinleitung und eine Reihe weiterer besonderer Befugnisse übertragen war. Für diese Vertreter hatten die Regierungen jeweils selbst aufzukommen.

Art. 256 lit. b enthielt selbst nur eine einzige $\mathrm{Zu}$ ständigkeit und verwies im Übrigen auf die Abschnitte III, IV, V und VII, die die Feststellung von Entschädigungssummen, ${ }^{209}$ Ernennungsbefugnisse,210 Kompetenzen im Zusammenhang mit Vollstreckungsmaßnahmen und richterlichen Maßnahmen der Monarchie, ${ }^{211}$ im Clearingverfahren $^{212}$ und in Bezug auf die Verträge ${ }^{213}$ sowie die

während des Krieges wegen Versäumung einer Handlung oder Nichtwahrung einer Formvorschrift getroffen wurden (ausgenommen es besteht eine Zuständigkeit eines Gerichts der AAM), Antrag auf Wiederherstellung des beeinträchtigten Rechtszustands möglich; Art. 254 Abs. 2, 4: Herstellung der Rechtslage vor Erlass der betreffenden Maßnahme bei Verletzung des Rechts auf rechtliches Gehör eines Staatsangehörigen der AAM durch Gerichtsentscheidungen und Exekutionsmaßnahmen während des Krieges (auf Antrag des betroffenen Staatsangehörigen).

${ }^{212}$ Art. 248, Anlage § 16 Abs. 1: bei Uneinigkeit zweier Ämter über das tatsächliche Bestehen einer Schuld oder Streitigkeit außerhalb der Ämter; Art. 248, Anlage $\S 20$ : als Berufungsinstanz gegen eine gemeinsame Entscheidung der Ämter.

${ }^{213}$ Art. 252 lit. d: Verpflichtung zur Wiederherstellung eines durch Aufhebung von Verträgen zwischen Feinden mangels Ausführung einer Bestimmung durch eine der Parteien oder aufgrund der Ausübung eines im Vertrag vereinbarten Aufhebungsrechts beeinträchtigten Rechtszustandes; Art. 256 lit. b: alle Streitfragen für die vor Inkrafttreten des VSG zwischen den Staatsangehörigen der AAM und österreichischen 
Wiedergutmachung nach Art. $257^{214}$ vorsahen. ${ }^{215}$ Hervorzuheben ist, dass diese Zuständigkeiten der Schiedsgerichte zum Teil obligatorisch und zum Teil fakultativ ausgestaltet waren. ${ }^{216}$

Gemäß Art. 256 lit. g sowie Art. 248, § 24 der Anlage hatten alle Vertragsparteien die Entscheidungen der Gemischten Schiedsgerichtshöfe anzuerkennen und verpflichteten sich $\mathrm{zu}$ ihrer Durchsetzung. Sie waren einem Rechtsmittel nicht zugänglich. Traf der Gemischte Schiedsgerichtshof eine negative Entscheidung über seine sachliche Zuständigkeit im Clearingverfahren, d.h. stellte er fest, dass ein Anspruch nicht zu den in Art. 248 vorgesehen Fällen zählte, wurden dadurch andere Möglichkeiten der Geltendmachung aber nicht präkludiert (Art. 248, § 23 der Anlage). Gerade die Frage der Kompetenz der Schiedsgerichtshöfe, genauer der Möglichkeit, über ihre eigene Kompetenz verbindlich zu entscheiden, sollte in der weiteren Entwicklung des Völkerrechts Beachtung erfahren. So berief sich die ILC in ihren Plänen über den Entwurf einer Schiedsgerichtsordnung in den 1950er-Jahren auf ein ,auch in den Verfahrensordnungen zahlrei-

Staatsangehörigen geschlossenen Verträge (ausgenommen jene, die nach den Gesetzen der AAM oder der neutralen Mächte in die Zuständigkeit ihrer Gerichtsbarkeit fallen, auf Antrag eines der beteiligten Staatsangehörigen der AAM auf in diesen Fällen).

${ }^{214}$ Falls ein zuständiges Gericht in den Angelegenheiten, die gemäß Abschnitt III, IV, V und VII in die Kompetenz des Gemischten Schiedsgerichtshofes fielen, ein gegen diese Bestimmungen verstoßendes Urteil gefällt hat(te), erkannte der Gem. Schiedsgerichtshof über den Anspruch auf Wiedergutmachung, wobei Art. 257 gem. Art. 251 von vornherein nicht gegenüber den Vereinigten Staaten oder ihren Staatsangehörigen galt. ${ }^{215} \mathrm{Zu}$ den Entscheidungen der Gemischten Schiedsgerichte vgl. BLÜHDORN, Rechtssätze, sowie im Einzelnen die offiziellen Entscheidungssammlungen (Tribunaux arbitraux mixtes, Recueil).

${ }^{216}$ DE AuER, Competency 221.

217 Commission du droit International, Procedure Arbitrale 46, Übersetzung der Autorin.

${ }^{218}$ Besonderes Aufsehen hatte eine heftig kritisierte, aber letztendlich anerkannte Entscheidung des rumä- cher nach dem ersten Weltkrieg eingesetzter gemischter Schiedsgerichte anerkanntes “217 Prinzip des internationalen Rechts, internationalen Schiedsgerichten die Entscheidungshoheit über ihre eigene Kompetenz zu überlassen.218

\subsection{Die Europäische und die Internationale Donaukommission (Abschnitt II)}

Vor 1914 hatte für die Donau kein einheitliches Regime bestanden. ${ }^{219}$ In Bezug auf die Reglementierung konnten drei Abschnitte unterschieden werden: Die untere Donau, die in die Zuständigkeit der 1856 geschaffenen Europäischen Donaukommission ${ }^{220}$ fiel, die mittlere Donau (bis zum Eisernen Tor an der [heutigen] serbisch-rumänischen Grenze), über die die Uferstaaten (Rumänien, Bulgarien und Serbien) ihre jeweilige territoriale Souveränität ausübten und schließlich die obere Donau (Eisernes Tor bis Ulm), deren Verwaltung durch die Schifffahrtsakte von 1857 zwischen den dortigen Uferstaaten (Österreich-Ungarn, Bayern und Baden-Württemberg) geregelt war. ${ }^{221}$ In den Pariser Friedensverträgen erfolgte die Erklärung der Donau von Ulm bis zur Mündung zu einem

nisch-ungarischen gemischten Schiedsgerichtshofs erregt, in dem er seine Kompetenz restriktiv ausgelegt und sich für unzuständig erklärt hatte. Vgl. Commission du droit International, Procedure Arbitrale 47 sowie DE AUER, Competency 26-29.

219 Eine Übersicht über das Donaurecht bis zum Ersten Weltkrieg gibt OtTATHAL-OTTENHORST, Völkerrechtliche Stellung 56-58.

${ }^{220}$ Eine „Europäische Donaukommission" war ursprünglich gleichzeitig mit der „Kommission der Donau-Uferstaaten“ im dritten Pariser Frieden vom 30. 3. 1856 eingesetzt worden, wobei nur letztere gemäß Art. 17 und 18 des Pariser Friedens auf Dauer angelegt war; letzten Endes wurde jedoch nicht die Europäische Kommission, sondern die der Uferstaaten aufgelöst, und erstere übernahm alle der zunächst zwischen den beiden Kommissionen geteilten Aufgaben. Vgl. THIEMEYER, Donau-Schifffahrt 206f. Ausführlich von den Anfängen bis zum Krieg auch Donaukommission, Commission Européenne 6-37.

${ }^{221}$ Ebd. 40. 
internationalen Fluss (im VSG in Art. 291), künftig $\mathrm{zu}$ verwalten von der wiedererrichteten Donaukommission. Im Gegensatz zu Rhein, Elbe und Oder war das bis dahin in den Verträgen vorgesehene Regime für die Donau ein bloß provisorisches, was der zuständige Ausschuss auf der Friedenskonferenz mit den zahlreichen unterschiedlichen Interessen begründete: Eine endgültige Regelung sei weder möglich noch notwendig. ${ }^{222} \mathrm{Er}$ schlug vor, zunächst eine Kommission, bestehend aus Vertretern der USA, Großbritanniens, Frankreichs, Italiens, Belgiens, Griechenlands, Rumäniens, Serbiens und der Tschechoslowakei, an der die ehemaligen Feindstaaten frühestens nach einem Jahr teilnehmen können sollten, einzurichten, um über das definitive Statut $\mathrm{zu}$ beraten.223 Art. 304 VSG verpflichtete Österreich schließlich zur Anerkennung dieser noch zu beschließenden Donauordnung, die auf einer binnen eines Jahres nach Inkrafttreten des Vertrages zusammentretenden Tagung der alliierten und assoziierten Mächte, an der Österreichs Vertreter (mit beratender Stimme ${ }^{224}$ ) ebenfalls teilnehmen konnten, beschlossen werden sollte.

Gemäß Art. 301 sollte die Europäische Donaukommission - mit den Zuständigkeiten vor dem Krieg - wiedererrichtet werden, vorläufig nur mit den Mitgliedsstaaten Großbritannien, Frankreich, Italien und Rumänien. Diese hielt bereits von 15.17. Oktober 1919 ihre erste außerordentliche Sitzung ab, an der nur die Vertreter der drei europäischen Alliierten vertreten waren; die erste ordentliche Sitzung fand im Mai 1920 statt. Ein wesentlicher organisatorischer Unterschied zur Europäischen Kommission vor dem Krieg bestand darin,

\footnotetext{
222 Ebd. 41.

${ }^{223} \mathrm{Ebd}$.

${ }^{224} \mathrm{Ebd}$

2251920 waren dies Legrand (Frankreich), Baldwin (GB), Comte Dentice di Frasso (Italien) und Contzesco (Rumänien). Siehe Donaukommission, Commission Europeénne 80.

${ }^{226}$ Ebd. 68. Die Ersatzmitglieder waren die jeweiligen Konsuln bzw. - im Falle Rumäniens - der Erste Präsident des Berufungsgerichts in Galați.
}

dass den Vertretern 225 nunmehr Ersatzmitglieder zur Seite gestellt wurden, da die vielfältigen Aufgaben nach dem Krieg die regelmäßige Anwesenheit der Vertreter am Sitz der Kommission im rumänischen Galatz [Galați] erschwerten. ${ }^{226}$ In dieser Kommission wechselte der Vorsitz alphabetisch, die Entscheidungen wurden grundsätzlich mit Mehrheit getroffen. ${ }^{227}$ Die ordentliche Sitzung fand zweimal im Jahr, im Frühjahr und im Herbst, statt;228 für die Umsetzung der dort gefassten Beschlüsse und die laufende Verwaltung bestand ein Exekutivkomitee. ${ }^{229}$

$\mathrm{Ab}$ dem (geographischen) Ende der Zuständigkeit der Europäischen Donaukommission wurde die provisorische Verwaltung der Donau einer internationalen Kommission übertragen. Diese Internationale Donaukommission sollte ihrerseits die 1919 von der Friedenskonferenz eingesetzte interalliierte Kommission ablösen und bestand je aus einem Vertreter Bayerns und Württembergs sowie der übrigen Uferstaaten (Österreich, Tschechoslowakei, Ungarn, Jugoslawien, Rumänien, Bulgarien) und je einem Vertreter der Nichtuferstaaten, die auch in der Europäischen Donaukommission vertreten waren, mithin Frankreich, Großbritannien und Italien (Art. 302 VSG). Zum Präsidenten der Internationalen Donaukommission wurde auf ihrer ersten Tagung in Paris im Juni 1920 der Vertreter Großbritanniens, Admiral Ernest Troubridge gewählt, 230 der bereits als Befehlshaber der Donauschifffahrt fungiert 231 und die Leitung der interalliierten Kommission innegehabt hatte. ${ }^{232}$ Im September wurden Richtlinien für ihre innere Organisation

\footnotetext{
${ }^{227}$ Ebd. $79 f$.

${ }^{228}$ Ebd. 68.

${ }^{229}$ Ebd. 72.

${ }^{230}$ NEISSER, Volkswirtschaftliche Chronik 272.

${ }^{231}$ Wiener Zeitung, Nr. 276 v. 1. 12. 1918, 2.

${ }^{232}$ Vgl. Neues Wiener Tagblatt, Nr. 165 v. 17. 6. 1919, 15.
} 
geschaffen, ${ }^{233}$ die schließlich jener der Europäischen Donaukommission ${ }^{234}$ gleichen sollte. Als erste Aufgaben der Kommission hatte Art. 303 Abs. 4 VSG die Zuerkennung von Lotsenlizenzen, die Regelung der Lotsengelder und die Kontrolle des Diensts der Lotsen vorgesehen; die rein "technische und wirtschaftliche“ Zielsetzung der Kommission, deren „,vornehmste Aufgabe in der Wiederbelebung und Entwicklung des Donauverkehrs" bestünde, spiegelte sich fürderhin auch im Selbstverständnis der Kommission wieder. ${ }^{235}$

Entsprechend den Vorgaben der Verträge fand im August 1920 in Paris die Donaukonferenz statt, an der neben den Vertretern der europäischen Alliierten ${ }^{236}$, Belgiens, Griechenlands, des SHS-Staats und der Tschechoslowakei auch die Vertreter der Kriegsverlierer Deutschland, Österreich, ${ }^{237}$ Ungarn und Bulgarien teilnahmen. Nach einem Jahr wurden am 23. Juli 1921 zwischen allen Staaten die 44 Artikel des definitiven Donaustatuts beschlossen. ${ }^{238}$ Darin wurde die Verwaltung durch die zwei bereits bestehenden Kommissionen, die internationale und die europäische, in derselben Zusammensetzung wie in den

\footnotetext{
${ }^{233}$ NEISSER, Volkswirtschaftliche Chronik 346.

${ }^{234}$ Im Gegensatz zu dieser wurde das Personal jedoch von den einzelnen Staaten finanziert, siehe OTTATHALOTTENHORST, Völkerrechtliche Stellung 70 - vgl. auch Art. 303 Abs. 2 VSG.

235 Rede von Präsident Troubridge auf der 3. Tagung der Internationalen Donaukommission in Wien im Dezember 1920, NEISSER, Volkswirtschaftliche Chronik 423.

${ }^{236}$ Die USA waren eingeladen worden, hatten aber auf eine Teilnahme verzichtet. Donaukommission, Commission Européenne 43.

237 Österreich wurde - wie auch bei den Verhandlungen über die Aufteilung der Flussschiffe, dazu noch unten - durch Sektionschef Minsterialrat Dr. Wilhelm Ondraczek vertreten. Ebd. 41. Dieser hatte bereits an den Friedensverhandlungen als Vertreter des Staatsamtes für Handel und Gewerbe, Industrie und Bauten teilgenommen, vgl. Friedensdelegation, Bericht I 3.

${ }^{238} \mathrm{Ebd}$. 43. Ein auf fünf Jahre nach ihrem Inkrafttreten am 1.10. 1922 befristetes Antragsrecht auf Revision wurde nicht in Anspruch genommen. Ebd. 43f.
}

Friedensverträgen vorgesehen, auf Basis der Schiffahrtsfreiheit und Flaggengleichheit bestätigt. ${ }^{239}$ Beide Kommissionen, die als Verwaltungsunionen anzusehen waren, ${ }^{240}$ sollten bis zum Zweiten Weltkrieg bestehen bleiben; ${ }^{241}$ die heutige Donaukommission wurde mit dem Übereinkommen über die Regelung der Donauschifffahrt vom 18. August 1948 geschaffen. ${ }^{242}$

\subsection{Verteilung der Flussschiffe (Abschnitt II)}

Die Abtretung und Aufteilung der Flussschiffe sah der VSG aus zwei verschiedenen (Rechts-) Gründen vor, dem der Reparation (Art. 179, Anlage III, §5) und zum Zweck der Nutzung der durch Art. 291 für international erklärten Flussgebiete (Art. 300 Abs. 1). ${ }^{243}$ Ersteres betraf gem. Art. 179, Anlage III, § 5 Abs. 1 alle (identifizierbaren) Flussschiffe und anderen Fahrzeuge der Flussschifffahrt, die seit dem 28. Juli 1914 (unter welchem Rechtstitel auch immer) in den Besitz Österreichs oder seiner Staatsangehörigen gelangt waren, sowie - gem. Abs. 2 leg.cit. - als Ersatz für den durch diese Rückgaben nicht abge-

${ }^{239}$ Ebd. 44.

${ }^{240}$ Dazu OtTATHAL-OTtENHORST, Völkerrechtliche Stellung 60-62.

241 Während die Internationale Donaukommission durch den Wiener Vertrag vom 12.9. 1940 aufgelöst worden war, bestand bis über die Belgrader Konferenz 1948 hinaus jedoch Uneinigkeit zwischen den Westmächten und der UdSSR über die Gültigkeit der Pariser Konvention 1921 und den Weiterbestand der Europäischen Donaukommission. Vgl. PICHLER, Donaukommission 21-23.

242 Das Übereinkommen findet sich online auf der Website der Donaukommission unter https://www.danubecommission.org/dc/en/danubecommission/convention-regarding-the-regime-of-navigation-on-the-danube/(23. 3. 2020).

${ }^{243}$ Dies betraf auf österreichischem Gebiet insbesondere die Donau und Teile von March und Thaya. 
deckten kriegsbedingten Verlust an Schifffahrtstonnengehalt der AAM einen Teil des österreichischen Flussfahrzeugparks, höchstens jedoch $20 \%$ des Gesamtbestandes vom 3. November 1918. Diese aus dem Titel der Reparation zu leistenden Teile waren auf die Gesamtmenge der abzutretenden Schiffe anzurechnen, die gem. Art. 300 Abs. 1 auch einen Teil der in den Häfen der betroffenen Flussgebiete registrierten Schlepper und Boote sowie des benötigten Materials umfasste. Die Entscheidung über die Zahl der abzutretenden Schlepper und Boote, die Menge des abzutretenden Materials und die Verteilung (Abs. 2 leg.cit.) sowie über die Einzelheiten der Abtretung aus dem Titel der Reparation gem. (Art. 179, Anlage III, §5 Abs. 2) hatte gem. Art. 179, Anlage III, §5 Abs. 3 durch Schiedsspruch zu erfolgen. ${ }^{244}$ Im Unterschied zu den aus dem Titel der Reparation geschuldeten Gegenständen war bei Eigentumsübertragungen gem. Art. 300 Abs. 4 jedoch eine Entschädigung an die früheren Eigentümer zu entrichten und ihr Wert gegebenenfalls der Wiedergutmachungs- bzw. „Befreiungsschuld“ anzurechnen. Auch über Art und Höhe dieser Entschädigung bzw. der Wiedergutmachungsgutschrift entschied nicht die Reparationskommission, sondern der oder die Schiedsrichter. ${ }^{245}$ Bis zur schiedsrichterlichen Entscheidung über die endgültige Aufteilung war die Aufsicht über die Schiffe einem Aus-

${ }^{244}$ Die Regelung des Verfahrens zur Rückgabe der gem. Art. 179, Anlage III, § 5 Abs. 1 VSG in natura zurückzustellenden Schiffe oblag jedoch der Reparationskommission.

${ }^{245}$ Für die Organisation der Rückerstattung der aus dem Titel der Reparation geschuldeten Gegenstände war nach Art. 179, Anlage III, § 5 Abs. 1 jedoch wiederum die Reparationskommission, an die diese gem. Abs. 2 auch auszuliefern waren, zuständig.

${ }^{246}$ Gem. Art. 300 Abs. 7 hatte diese Verwaltung auf kaufmännischer Grundlage zu erfolgen. Die Entscheidung über die Verwertung der Gesamteinnahmen lag ebenfalls bei der Reparationskommission. schuss zu übertragen, der primär „die Verwertung dieser Schiffe im allgemeinen Interesse durch irgendeine lokale Organisation sicherzustellen" und nur in zweiter Linie unmittelbar wahrzunehmen hatte (Art. 300 Abs. 6).246

Dieser Ausschuss war aus Vertretern der AAHM mit Ausnahme Japans zu bilden (Art. 300 Abs. 6); zur Ernennung des Schiedsrichters bzw. der Schiedsrichter wurden in Art. 300 Abs. 2 die USA berufen. Diese ernannten im Mai 1920 Walker Hines, den ehemaligen Generaldirektor der amerikanischen Eisenbahnverwaltung, ${ }^{247}$ in diese Funktion, ${ }^{248}$ der auch für die strittigen Fragen über die Aufteilung des deutschen Schiffparks zuständig war. ${ }^{249}$ Das Ineinandergreifen ihrer Tätigkeiten machte eine Abstimmung des Schiedsrichters und der Reparationskommission notwendig. Für den 23. Juli 1920 waren daher sowohl Hines als auch der Präsident der internationalen Donaukommission zur Sitzung der österreichischen Sektion der Reparationskommission geladen, um die weitere Vorgehensweise $\mathrm{zu}$ besprechen. ${ }^{250}$ Die Verhandlungen vor dem Schiedsrichter mit allen betroffenen Staaten fanden jedoch erst im Februar 1921 statt, als in Paris die Vorbereitungen für die Donaukonferenz im April begonnen hatten, wo die Aufteilung des Donauschiffahrtsparks ebenfalls auf der Tagesordnung stand. ${ }^{251}$ Bei den dreiwöchigen Verhandlungen erhielten alle beteiligen Staaten die

${ }^{247}$ Dieser war der Öffentlichkeit bereits als solcher aus der Berichterstattung bekannt, vgl. z.B. Der Neue Tag, Nr. 1 v. 23. 3. 1920, 13.

${ }^{248}$ Die Notifizierung an die Botschafterkonferenz erfolgte am 14.5.1920, Die Friedensverhandlungen, Wiener Zeitung, Nr. 110 v. 15. 5. 1920, 9. Ihm zur Seite stand als Sekretär und Assistent Oberst Arthur B. Kratz, für seine Wiener Aufenthalte stand im Staatsamt für Heereswesen ein ständiges Büro zur Verfügung. Vgl. Neue Freie Presse, Nr. 20084 v. 27. 7. 1920, 5.

${ }^{249}$ Vgl. Neue Freie Presse, Nr. 20288 v. 20. 2. 1921, 13.

${ }^{250}$ Neues Grazer Abendblatt, Nr. 483 v. 19. 7. 1920, 2.

${ }^{251}$ Neues Montagblatt, Nr. 17 v. 25. 4. 1921, 3. 
Gelegenheit, ihren zumeist bereits schriftlich vorgebrachten Standpunkt vor dem Schiedsrichter $\mathrm{zu}$ vertreten. ${ }^{252} \mathrm{Um}$ sich selbst einen Überblick über die Gegebenheiten zu machen, unternahm Hines vor Fällung seiner endgültigen Entscheidung zusätzlich von Wien aus im Frühjahr 1921 noch eine ursprünglich nur für wenige Tage geplante Studienreise entlang der Donau, ${ }^{253}$ die letzten Endes rund drei Wochen dauern sollte. ${ }^{254}$ Schließlich wurde die ursprünglich für Ende Juni erwartete $^{255}$ Entscheidung 256 am 2. August bekanntgegeben. ${ }^{257}$

Im Mittelpunkt stand die Frage, ob die bei Kriegsende von den Nachfolgestaaten und Frankreich beschlagnahmten Schiffe als Kriegsbeute rechtmäßig beansprucht worden waren oder aber als Privatbesitz zu qualifizieren und zu restituieren seien. Österreich hatte sich - wie auch Ungarn - auf die Haager Konvention berufen und auf den Standpunkt gestellt, dass die Schiffe Privateigentum der Donaudampfschifffahrtsgesellschaft (bzw. ihres ungarischen Pendants) waren, während Rumänien und Frankreich betont hatten, dass diese Schiffe in die Organisation der Militärtransporte eingebunden waren. Da die Donau ein internationaler Fluss

${ }^{252}$ Neues Montagblatt, Nr. 17 v. 25. 4. 1921, 3. Als Vertreter Österreichs waren Sektionschef Ondraczek vom Verkehrsministerium und Hofrat Friedrich Csatáry, der Generaldirektor der Donau-Dampfschiffahrtsgesellschaft, nach Paris gereist.

${ }^{253}$ Neue Freie Presse, Nr. 20322 v. 26. 3. 1921, 9.

${ }^{254}$ Neue Freie Presse, Nr. 20347 v. 22. 4. 1921, 2f.

${ }^{255}$ Montags-Zeitung, Nr. 2063 v. 13. 6. 1921, 6.

${ }^{256}$ Als Grund für die Verzögerung wurde die Ratifikation des Vertrags von Trianon genannt (CSATÁRY, Donau-Dampfschiffahrts-Gesellschaft 2).

${ }^{257}$ Vorarlberger Tagblatt, Nr. 187 v. 18. 2. 1921, 3.

${ }^{258}$ Montags-Zeitung, Nr. 2063 v. 13. 6. 1921, 6.

${ }^{259}$ Von besonderer Seite, Die Aufteilung der Donauflotte und die österreichische Binnenschiffahrt, in: Die Börse v. 18. 8. 1921, 4. Die Rückgabepflicht betraf Flussschiffe aus Privateigentum; die Schiffe, über die die Zentrale Transportleitung verfügt hatte, wurden den jeweiligen Staaten endgültig zugesprochen. Vgl. HINES, Determination 20-23. sei, fielen sie nicht in die Kompetenz des Schiedsrichters, sondern unterlägen als Kriegsbeute dem Prisenrecht; die Tschechoslowakei wiederum hob ihren Beitrag zur Finanzierung der Gesellschaften durch Subventionen. ${ }^{258}$ Der Schiedsspruch erklärte die Beschlagnahme des Großteils der Schiffe für rechtmäßig, nur etwa $15 \%$ sollten von Frankreich, Rumänien und Jugoslawien zurückgegeben werden.259 Im Gegenzug wurden die Ansprüche Serbiens und Rumäniens damit als erledigt angesehen, allein an die Tschechoslowakei waren - gegen Entschädigung - noch Schleppschiffe und Remorqueure ${ }^{260}$ abzutreten. Darüber hinaus musste auch eine Anzahl an Passagierschiffen übergeben werden. ${ }^{261}$

In Österreich war man sich der ungünstigen Ausgangslage bewusst, ${ }^{262}$ hatte aber dennoch auf die Restitution von Schiffen durch die Nachfolgestaaten gehofft, ${ }^{263}$ sodass die Entscheidung eine große Enttäuschung bedeutete. Insbesondere für die Donaudampfschifffahrtsgesellschaft stellte sie einen entscheidenden Einschnitt dar, betraf die Aufteilung schließlich etwa $45 \%$ des bei Kriegsausbruch bestehenden Schiffsparks. ${ }^{264}$

${ }^{260}$ Die Entscheidung des Schiedsrichters sah hier die abzutretende Gesamtmenge vor, über deren Aufteilung zwischen Deutschland, Österreich und Ungarn gesondert beraten und entschieden wurde, vgl. Von besonderer Seite: Die Aufteilung der Donauflotte und die österreichische Binnenschiffahrt, in: Die Börse v. 18. 8. 1921, 4 .

${ }^{261}$ Von besonderer Seite, Die Aufteilung der Donauflotte und die österreichische Binnenschiffahrt, in: Die Börse v. 18. 8. 1921, 4; Vorarlberger Tagblatt, Nr. 187 v. 18. 2. $1921,3$.

262 Neues Montagblatt Nr. 17 v. 25. 4. 1921, 3.

${ }^{263}$ Neues Wiener Tagblatt Nr. 53 v. 22. 2. 1921, 8.

${ }^{264}$ CSATÁRY, Donau-Dampfschiffahrts-Gesellschaft 2. Eine Aufstellung der abgetretenen Schiffe findet sich bei Donau-Dampfschiffahrtsgesellschaft, 125 Jahre 76. 


\subsection{Die Sachverständigenausschüsse über die Aufteilung der Eisenbahnen (Kapitel IV)}

Art. 318 regelte die allgemeinen Bedingungen zur Übertragung der abzutretenden Eisenbahnlinien. Während bei der Abtretung von Eisenbahnnetzen mit eigenem Wagenpark auch dieser als Ganzes mitabzutreten war, übertrug Abs. 1 Z. 3 leg.cit. für die übrigen Strecken ${ }^{265}$ die Aufteilung des Wagenparks des Eisenbahnnetzes, zu dem diese Strecken gehören, an von den AAM zu ernennende Sachverständigenausschüsse. Gemäß Art. 319 waren die Betriebsverhältnisse über nunmehr grenzüberschreitende (Zweig-)Linien, die Errichtung neuer Grenzbahnhöfe und die Betriebsführung zwischen diesen Bahnhöfen in Abkommen der beteiligten Eisenbahnverwaltungen zu regeln, wobei die Streitfragen ebenfalls durch gem. Art. 318 zusammengesetzte Sachverständigenausschüsse zu entscheiden waren.

Zur Zeit der Monarchie hatte ein gemeinsamer Wagenpark bestanden, über den - unabhängig von den Eigentumsverhältnissen im Einzelnen die k.u.k. Zentral-Transportleitung in Wien verfügungsbefugt gewesen war. Bei Kriegsende war ein Teil der Wagen als Kriegsbeute beschlagnahmt worden und der Rest über das gesamte Gebiet der ehemaligen Monarchie verstreut. ${ }^{266}$ Der Verkehr der Wagen des Gemeinschaftsparks war zum Erliegen gekommen, da die gemeinsamen Güterwagen im Gegensatz zu den Lokomotiven und Personenwagen nicht eindeutig einem Besitzer zuordenbar waren, und die jeweiligen Nachfolgestaaten aus der Befürchtung des Verschwindens heraus so viele Wagen wie möglich zurückhielten. Bis zur endgültigen Aufteilung durch die Fahrparkaufteilungskommission war als erste Abhilfe zwar ein

265 Dies betraf auch die Strecken des ehemaligen Russisch-Polen mit normaler Spurweite, die als abgezweigter Teil des österreichisch-ungarischen Eisenbahnnetzes galten und auf die die Vorschriften über die Aufteilung des Wagenparks gemäß Z. 3 und 4 leg.cit. explizit erstreckt wurden. gemeinsames Organ der Nachfolgestaaten, das Wagenumlaufkomitee in Wien, geschaffen worden, eine endgültige Übergangsregelung wurde jedoch erst auf einer 1921 organisierten Konferenz in Portorož (Istrien) im Wege mehrerer Übereinkommen zwischen den sieben Nachfolgestaaten getroffen. ${ }^{267}$

Die Fahrparkaufteilungskommission selbst befand sich bereits seit Herbst 1919 in Wien, da die Friedenskonferenz (Mitteilung an den österreichischen Botschafter Eichhoff am 18. Oktober) aufgrund des Kohlemangels in Österreich beschlossen hatte, sie bereits vor Inkrafttreten des Vertrages nach Wien zu entsenden. Das Plenum dieser provisorischen Kommission bestand aus je einem Vertreter Englands, Italiens, Jugoslawiens, Tschechoslowakiens, Rumäniens, Polens, der Republik Österreich und Ungarns, der Vorsitz lag in den Händen des englischen Delegierten, Sir Francis Dents. Im Plenum wurden mit Dreiviertelmehrheit der anwesenden Mitglieder - in Ermangelung einer solchen durch den Präsidenten - alle Fragen beschlossen, die mehr als zwei Staaten betrafen. Für die übrigen Fragen waren Unterkommissionen zuständig, die sich jeweils aus dem Präsidenten und den Vertretern des Material abtretenden Staates und des Staates, an den Material abgetreten wurde, zusammensetzten. Im Einzelfall waren sie auch zur Durchführung der Entscheidung der Plenarkommission zuständig. ${ }^{268}$

Bei der Aufteilung hatten die Ausschüsse gemäß Art. 318 Abs. 3 die Größe des für die betroffenen Strecken bei der letzten Bestandaufnahme vor dem 3. November 1918 verzeichneten Wagenparks, die Länge der Strecken einschließlich der Nebengeleise sowie die Art und den Umfang des

\footnotetext{
266 Wiener Montagblatt, Nr. 47 v. 21. 11. 1932, 4.

267 ENDERES, Eisenbahnverhandlungen 3.

${ }^{268}$ Reichspost Nr. 373 v. 20. 10. 1919, 3.
} 
Verkehres zu berücksichtigen. „Es war von vornherein klar, dass die Aufteilung von 250.000 Güterwagen, dann 33.000 Personen-, Gepäcks-, Dienst- und Postwagen sowie 12.000 Lokomotiven lange Zeit in Anspruch nehmen werde."269 Da Art. 318 Abs. 3 vorsah, dass die Kommissionen die Übernahmebedingungen zu regeln und die einzelnen abzutretenden Lokomotiven, Personen- und Güterwagen zu bestimmen hatten, war neben der Klärung der Rechtsfragen eine Zählung und Inventarisierung des vorhandenen Materials notwendig, sodass im November 1921 erst 40.000 Güterwagen und 3.000 Lokomotiven aufgeteilt worden waren. ${ }^{270}$ Mit Ende der Aufteilung 1932 verblieben den nunmehrigen österreichischen Bundesbahnen schließlich an regelspurigen Wagen 4.819 Personen-, 1.767 Gepäck(Dienst-), 259 Post-, 12.343 gedeckte und 11.444 offene Güterwagen, an schmalspurigen Wagen 230 Personen-, 38 Gepäck-, 105 gedeckte und 545 offene Güterwagen. ${ }^{271}$

\section{Zusammenfassung}

Betrachtet man die Zahl und Bedeutung der auf den Pariser Friedensverträgen im Allgemeinen, dem VSG im Besonderen, beruhenden Einrichtungen, erscheint es verwunderlich, dass dieses Kapitel der Zwischenkriegszeit ein weitgehend unbekanntes geblieben ist. Weniger überraschend stellt sich dagegen angesichts der Vielfältigkeit und Disparität der Einrichtungen, wie sie aus den obigen Ausführungen hervorgeht, die mangelnde Zusammenschau dar. Die Einrichtungen könnten sowohl in Bezug auf ihre Bedeutung, völkerrechtliche Stellung, Zusammensetzung, Aufgabenkreis, Dauer, die Rolle Österreichs, historische Entwicklung, ja selbst im Hinblick auf ihren Determinierungsgrad im Vertrag kaum ein bunteres Bild präsentieren. Ihnen allen gemein ist jedoch nicht nur die Verwurzelung im

\footnotetext{
${ }^{269}$ ENDERES, Eisenbahnverhandlungen 3.

270 Ebd. 3.
}

VSG, sondern auch ihre entscheidende Rolle im internationalen Gefüge der Zwischenkriegszeit.

\section{Korrespondenz:}

Mag. Laura R. RATHMANNER

Universität Wien

Institut für Rechtsphilosophie

Schenkenstraße 8-10

1010 Wien

laura.rosemarie.rathmanner@univie.ac.at

ORCID-Nr.: 0000-0002-1630-4135

\section{Abkürzungen:}

$\begin{array}{ll}\text { AAHM } & \begin{array}{l}\text { Alliierte und Assoziierte } \\ \text { Hauptmächte }\end{array} \\ \text { AAM } & \text { Alliierte und Assoziierte Mächte } \\ \text { AAng } & \text { Auswärtige Angelegenheiten } \\ \text { BKA/AA } & \text { Bundeskanzleramt/ } \\ & \text { Auswärtige Angelegenheiten } \\ \text { FRUS } & \text { Papers Relating to the Foreign } \\ & \text { Relations of the United States } \\ \text { GRA } & \text { Grenzregelungsausschuss } \\ \text { HÜA } & \text { Heeresüberwachungsausschuss } \\ \text { IKRK } & \text { Internationales Komitee } \\ \text { ILO } & \text { vom Roten Kreuz } \\ \text { LÜA } & \text { International Labor Organisation } \\ \text { MÜA } & \text { Luftüberwachungsausschuss } \\ \text { NAR } & \text { Marineüberwachungsausschuss } \\ \text { NPA } & \text { Neue Administrative Registratur } \\ \text { VSG } & \text { Neues Politisches Archiv } \\ \text { VV } & \text { Vertrag von St. Germain } \\ \text { ZGK } & \text { Vertrag von Versailles } \\ \text { Zentralgrenzkommission }\end{array}$

Siehe auch das allgemeine Abkürzungsverzeichnis: [http://www.rechtsgeschichte.at/media/abk.pdf]
${ }^{271}$ Wiener Montagblatt, Nr. 47 v. 21. 11. 1932, 4. 


\section{Literatur und gedruckte Quellen:}

Paul De AuER, The Competency of Mixed Arbitral Tribunals, in: Transactions of the Grotius Society 13 (1927) 17-30.

ANONYMUS („O.“), International Arbitrations under the Treaty of St. Germain, in: The British Year Book of International Law 4 (1923-24) 124-130.

Archivinformationssystem OeStA, KA NL 148 (B,C) Bernhard, Alfons, 1875.11.02-1954.08.14

[https://www.archivinformationssystem.at/detail.aspx?ID=75699] (15.1.2020).

Manfred BANSLEBEN, Liquidation des Weltkrieges und Rekonstruktion im Donauraum: Österreich und die nicht-deutschen Reparationen nach St. Germain, in: Österreich in Geschichte und Literatur 38 (1994) $1-21$.

Rudolf BLÜHDORN, Die Rechtssätze der gemischten Schiedsgerichte (Wien 1923).

Olivier BuIRETTE, „Réparer la guerre!“. Histoire de la formation et des premiers travaux de la Commission Interalliée des Réparations de Guerre appliqué aux alliés de l'Allmagne: Autriche, Hongrie et Bulgarie, 1919-20 (Paris 2005).

Commission des Réparations (Hg.), Annexe Nr. 1141. Revendications de la Belgique concernant le Triptyque de Saint Ildephonse et le Trésor de l'Ordre de la Toison d'Or. Rapport du Comité des Trois Juristes. [https://archive.org/details/belgianclaimstot00allirich/page/n1] (21. 10. 1921 / 21. 2. 2019).

Commission du droit International (Hg.), Procedure Arbitrale. Commentaire relatif au projet sur la procedure arbitrale (préparé par 1 Sécretariat, 5. 5. 1953).

Conférence de la paix, 1919-1920 (Hg.), Recueil des actes de la Conférence. Partie IV. B. Questions générales. 2. Commission des responsabilités des auteurs de la guerre et sanctions (Paris 1922).

Conférence de la paix, 1919-1920 (Hg.), Recueil des actes de la Conférence. Partie VI: Traité avec les puissances ennemies. Mise en vigueur A. Préparation de la mise en vigueur (Paris 1934).

Friedrich CSATÁRY, Die Entwicklung der DonauDampfschiffahrts-Gesellschaft, in: Die Börse v. 1. 7. 1921, 2.

Deutschösterreichische Friedensdelegation in St. Germain-en-Laye (Hg.), Bericht über die Tätigkeit der Deutschösterreichischen Friedensdelegation in St. Germain-en-Laye, 2 Bde. (Wien 1919).

Rudolf Dolzer, Mixed Claims Commissions, in: Max Planck Encyclopedia of Public International Law (Mai 2011/ 19. 1. 2019).
Marion DotTeR, Stefan WedRAC, Der hohe Preis des Friedens. Die Geschichte der Teilung Tirols 19181922 (Innsbruck-Wien 2018).

Philipp EGgER, Die Teilung Tirols nach dem Ersten Weltkrieg im Spiegel der Akten des österreichischitalienischen Grenzregelungsausschusses im Staatsarchiv Wien mit fachdidaktischer Ausarbeitung (phil. Dipl.-Arbeit, Univ. Innsbruck 2018).

Bruno ENDERES, Die Eisenbahnverhandlungen in Portorose, in: Neue Freie Presse, Nr. 20563 v. 27.11.1921, 3-4.

Erste Donau-Dampfschiffahrtsgesellschaft (Hg.), 125 Jahre Erste Donaudampfschiffahrtsgesellschaft (1829-1954) (Wien 1954).

Europäische Donaukommission (Hg.), La Commission Européenne du Danube et son oeuvre de 1856 à 1931 (Paris 1931).

Comment by Pierre-Marie DupuY, Proliferation of Actors, in: Volker RöBEN, Rüdiger WOLFRUM (Hgg.), Developments 537-542.

Ursula FREISE, Die Tätigkeit der alliierten Kommissionen in Wien nach dem Ersten Weltkrieg (phil. Diss., Univ. Wien 1963).

René FÜLÖP, „Die neue Notenbank. Eine Unterredung mit Gouverneur Dr. Spitzmüller", in: Die Börse Nr. 3 v. 25. 11. 1920, 1f.

Wilhelm G. GREWE, The epochs of international law (Berlin-New York 2000).

Jürgen HeIDEKING, Areopag der Diplomaten. Die Pariser Botschafterkonferenz der alliierten Hauptmächte und die Probleme der europäischen Politik 1920-1931 (= Historische Studien 436, Husum 1979).

Walker D. HINES, In the Matter of Questions arising as to Danube Shipping under Articles 339 of the Treaty of Versailles, 300 of the Treaty of Saint-Germain, 284 of the Treaty of Trianon, and 226 of the Treaty of Neuilly-Sur-Seine. The Arbitrators Determination of the Permanent Allocation of Vessels in Dispute, and of the Amount and Specifications of Cessions, and the Notification therunder (Paris 1921).

Yves Huguenin-BergenAt, Kulturgüter bei Staatensukzession. Die internationalen Verträge Österreichs nach dem Zerfall der österreichisch-ungarischen Monarchie im Spiegel des aktuellen Völkerrechts (= Schriften zum Kulturgüterschutz, Berlin u.a. 2010).

W. HummelberGer, Metzner, Hugo (1882-1926), Offizier und Ballistiker, in: Österreichisches Biographisches Lexikon 1815-1950, Bd. 6 (Lfg. 28, Wien 1974) 253. [https://www.biogra- 
phien.ac.at/oebl/oebl_M/Metz-

ner_Hugo_1882_1926.xml;internal\&action=hilite.action\&Parameter=Metzner $\left.{ }^{*}\right]$

(1974/15. 1 . 2020).

Stephen B. JONES, Boundary-Making. A handbook for statesmen, treaty editors and boundary commissioners (= Monograph series of the Carnegie Endowment for international Peace: Division of International Law 8, Washington, D.C. 1945).

Kärntner Landesarchiv (Hg.), Der 10. Oktober 1920. Kärntens Tag der Selbstbestimmung. Vorgeschichte-Ereignisse-Analysen (Wien 22009, Nachdruck 2019).

Hans KeRnBAUER, Währungspolitik in der Zwischenkriegszeit. Geschichte der österreichischen Nationalbank von 1923 bis 1938 (Wien 1991).

Sebastian KNEISEL, Schiedsgerichtsbarkeit in Internationalen Verwaltungsunionen (1874-1914). Die Verrechtlichung der zwischenstaatlichen Streitbeilegung (= Studien zur Geschichte des Völkerrechts 20, Baden-Baden 2009).

Heinz KÖNIG, Österreichs Grenzen. Kommentar zu Art. 27-35 VSG unter Berücksichtigung der Art. 36, 48, 55 betreffend die Grenzregelungsausschüsse (im Druck).

Alphons LHOTSKY, Die Verteidigung der Wiener Sammlungen kultur- und naturhistorischer Denkmäler durch die Erste Republik, in: MIÖG 63 (1955) 614-649.

Margaret MaCMillan, Paris 1919. Six Months that changed the World. (New York 2002).

Jürgen NAUTZ (Hg.), Unterhändler des Vertrauens. Aus den nachgelassenen Schriften von Sektionschef Dr. Friedrich Schüller (= Studien und Quellen zur österreichischen Zeitgeschichte 9, Wien-München 1990).

Karl NEISSER, Volkswirtschaftliche Chronik 11 (1920) 165.

Georg OtTATHAL-OtTENHORST, Die völkerrechtliche Stellung der Europäischen und der Internationalen Donaukommission, in: Jahrbuch der Konsularakademie zu Wien (1936) 56-75.

Papers Relating to the Foreign Relations of the United States (FRUS), The Paris Peace Conference, 1919, Bd. IV (Washington 1943).

Franz PICHLER, Die Donaukommission und die Donaustaaten: Kooperation und Integration (= Schriftenreihe der österreichischen Gesellschaft für AuBenpolitik und internationale Beziehungen 8, Wien-Stuttgart 1973).

Nicole PIETRI, La Société des Nations et la reconstruction financière de l'Autriche 1921-1926 (Genève 1970).
Ramon PILS, Kommentar zu den Art. 248-257 VSG (im Druck).

Laura RATHMANNER, Die Reparationskommission nach dem Staatsvertrag von St. Germain, in: BRGÖ 6 (2016) 74-98.

August ReINISCH (Hg.), Österreichisches Handbuch des Völkerrechts, Bd. 1: Textteil (Wien ${ }^{52013) . ~}$

Paul RichtER, Der Kampf um die Befreiung der Kriegsgefangenen, in: Tagblatt, Nr. 65 v. 19. 3. 1922, 1-2.

Christian Manfred RusT, Deutschland und die Nachkriegsordnung. Großbritannien, die Vereinigten Staaten und die Grundlagen einer Friedensregelung mit Deutschland in Paris 1919 und Jalta/Potsdam 1945 (phil. Diss., Freie Univ. Berlin 2001).

Volker RÜBENS, Environmental Treaty Bodies, in: Max Planck Encyclopedia of Public International Law (February 2015/ 30. 1. 2019).

Josef SCHENK, Abrechnungsschuldvereinbarungen, in: Neues Wiener Tagblatt Nr. 238 v. 30. 8. 1922, 7f.

W[alter] SAUER, Slatin Rudolf (Anton Carl) Pascha, Sir, Frh. von, Offizier und Kolonialbeamter, in: ÖBL 1815-1950, Bd. 12 (Wien 2004) 350.

Peter-Tobias STOLL, Human Rights, Treaty Bodies, in: MPEPIL (May 2008/ 30. 1. 2019).

Leopold STRENN, Von der Josefstadt in die Welt. Streiflichter durch das Militärgeographische Institut, in: Bezirksmuseum Josefstadt (Hg.), Aus der Josefstadt in die Welt. Landkarten aus dem 8ten. Begleitbuch zur gleichnamigen Ausstellung im Bezirksmuseum Josefstadt 9. März 2017-20 (Wien 2018) 15-67.

Guido THIEMEYER, Die Integration der Donau-Schifffahrt als Problem der europäischen Zeitgeschichte, in: Archiv für Sozialgeschichte 49 (2009) 303-318.

Christian TOMUSCHAT, International Courts and Tribunals, in: Max Planck Encyclopedia of Public International Law (April 2019/ 14. 10. 2019).

Tribunaux arbitraux mixtes, Recueil des décisions des tribunaux arbitraux mixtes, institúes par les traités de paix (Paris 1921-1930).

Charles DE VISSCHER, La Protection internationale des monuments historiques et des oeuvres d'art en temps de guerre, in: Revue de Droit International et de Légistation comparée 16 (3d serie) (1935) 3274, 246-288.

Sarah WAMBAUGH, Plebiscites since the World War. With a collection of official documents, 2 Bde. (Washington, D.C. 1933).

François WALTER, Gustave Ador, in: Historisches Lexikon der Schweiz [https://hls-dhs-dss.ch/fr/ articles/003848/2002-06-12/] (12.6. 2002/14. 10 . 2019). 
Josef WEISSENBACHER, Die Liquidation der österreichisch-ungarischen Bank (Diss., Hochschule für Welthandel Wien 1951).

Harald WiggenHORN, Verliererjustiz. Die Leipziger Kriegsverbrecherprozesse nach dem Ersten Weltkrieg (= Studien zur Geschichte des Völkerrechts 10, Baden-Baden 2005).

Rüdiger WOLFRUM, Introduction, in: Volker RÖBEN, DERs. (Hgg.), Developments of International Law in Treaty Making (= Beiträge zum ausländischen öffentlichen Recht und Völkerrecht 177, Berlin u.a. 2005) 1-13.

Anita ZiegerHOFER, Kommentar zu den Art. 173-176 VSG (im Druck).

Katja S. ZIEGLER, Jay-Treaty (1794), in: Max Planck Encyclopedia of Public International Law (April 2013/15. 10. 2019).

\section{Tageszeitungen und Periodika:}

Der Abruf der Presseorgane erfolgte über anno.onb.ac.at. Die Auswahl richtete sich nach Verbreitungsgebiet sowie Umfang und Qualität der einschlägigen Berichterstattung. Bei gleichlautenden Kurznotizen wird nur ein Nachweis zitiert.

Der Neue Tag

Deutsches Volksblatt

Die Börse

Innsbrucker Nachrichten

Montags-Zeitung

Neue Freie Presse

Neues Grazer Abendblatt

Neues Montagblatt

Neues Wiener Tagblatt

Prager Tagblatt

Reichspost

Salzburger Volksblatt

Wiener Montagblatt

Wiener Zeitung

Volkswirtschaftliche Chronik

Vorarlberger Tagblatt 